\title{
Numerical simulation and decomposition of kinetic energy in the Central Mediterranean: insight on mesoscale circulation and energy conversion
}

\author{
R. Sorgente ${ }^{1}$, A. Olita ${ }^{1}$, P. Oddo ${ }^{2}$, L. Fazioli ${ }^{1}$, and A. Ribotti ${ }^{1}$ \\ ${ }^{1}$ IAMC, Istituto per l'Ambiente Marino Costiero - Consiglio Nazionale delle Ricerche, Oristano, Italy \\ ${ }^{2}$ INGV, Istituto Nazionale di Geofisica e Vulcanologia, Bologna, Italy
}

Received: 30 March 2011 - Published in Ocean Sci. Discuss.: 24 May 2011

Revised: 28 July 2011 - Accepted: 10 August 2011 - Published: 22 August 2011

\begin{abstract}
The spatial and temporal variability of eddy and mean kinetic energy of the Central Mediterranean region has been investigated, from January 2008 to December 2010, by mean of a numerical simulation mainly to quantify the mesoscale dynamics and their relationships with physical forcing. In order to understand the energy redistribution processes, the baroclinic energy conversion has been analysed, suggesting hypotheses about the drivers of the mesoscale activity in this area. The ocean model used is based on the Princeton Ocean Model implemented at $1 / 32^{\circ}$ horizontal resolution. Surface momentum and buoyancy fluxes are interactively computed by mean of standard bulk formulae using predicted model Sea Surface Temperature and atmospheric variables provided by the European Centre for Medium Range Weather Forecast operational analyses. At its lateral boundaries the model is one-way nested within the Mediterranean Forecasting System operational products.

The model domain has been subdivided in four subregions: Sardinia channel and southern Tyrrhenian Sea, Sicily channel, eastern Tunisian shelf and Libyan Sea. Temporal evolution of eddy and mean kinetic energy has been analysed, on each of the four sub-regions, showing different behaviours. On annual scales and within the first $5 \mathrm{~m}$ depth, the eddy kinetic energy represents approximately the $60 \%$ of the total kinetic energy over the whole domain, confirming the strong mesoscale nature of the surface current flows in this area. The analyses show that the model well reproduces the path and the temporal behaviour of the main known subbasin circulation features. New mesoscale structures have been also identified, from numerical results and direct observations, for the first time as the Pantelleria Vortex and the Medina Gyre.
\end{abstract}

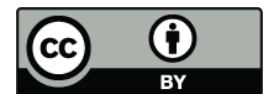

Correspondence to: R. Sorgente (roberto.sorgente@cnr.it)
The classical kinetic energy decomposition (eddy and mean) allowed to depict and to quantify the permanent and fluctuating parts of the circulation in the region, and to differentiate the four sub-regions as function of relative and absolute strength of the mesoscale activity. Furthermore the Baroclinic Energy Conversion term shows that in the Sardinia Channel the mesoscale activity, due to baroclinic instabilities, is significantly larger than in the other sub-regions, while a negative sign of the energy conversion, meaning a transfer of energy from the Eddy Kinetic Energy to the Eddy Available Potential Energy, has been recorded only for the surface layers of the Sicily Channel during summer.

\section{Introduction}

The Central Mediterranean region (CMED, hereafter), as previously defined by several authors (e.g. Astraldi et al., 1999; Ciappa, 2009), is a large area connecting the eastern and the western Mediterranean sub-basins. It is delimited by the eastern Sardinia Channel, the southern Tyrrhenian Sea and, mainly, the shallow ( $400 \mathrm{~m}$ ) Sicily Channel (Fig. 1), an intermediate basin with an average depth of $500 \mathrm{~m}$. It plays a crucial role in modulating the passage of the surface and intermediate water masses between the two Mediterranean sub-basins.

The highly irregular bottom topography of the Sicily Channel, in the form of a submarine ridge characterised by shallow banks along the Tunisian (Galite and Skerki banks) and Sicilian (Adventure Bank and Malta Channel area) coasts, further limits the water flow particularly at deeper levels. Flat-bottomed deep trenches are situated in the central part of the Sicily Channel, west of Malta, reaching depths of 1100-1200 m off Pantelleria, $1300 \mathrm{~m}$ off Linosa and $1650 \mathrm{~m}$ in the Malta Graben. The Tunisian and Libyan

Published by Copernicus Publications on behalf of the European Geosciences Union. 


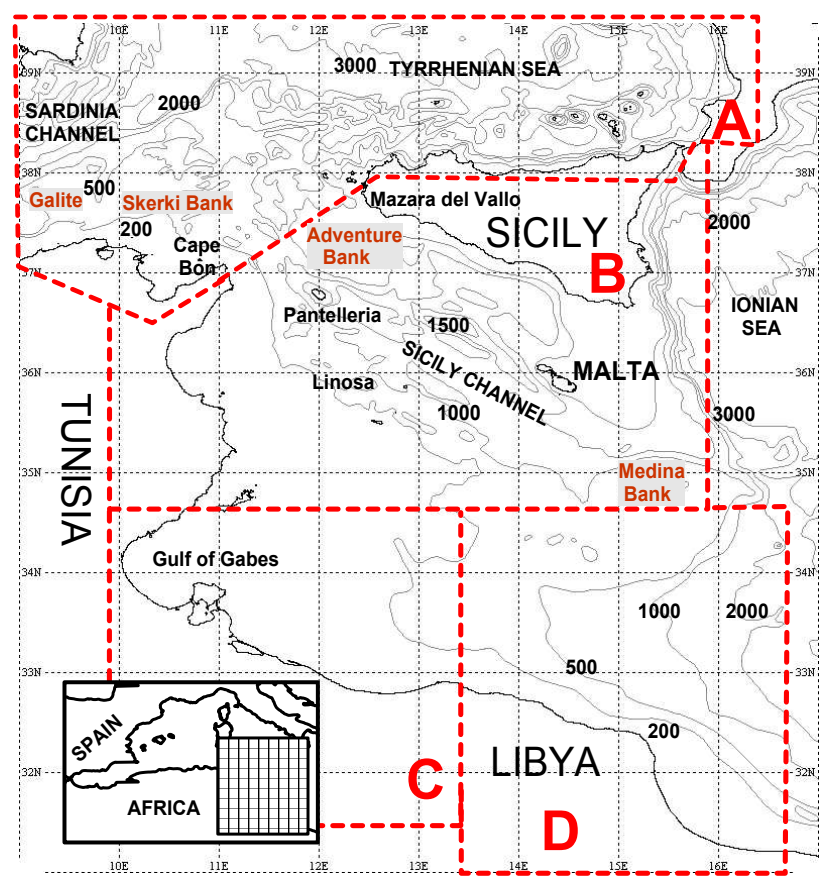

Fig. 1. The Central Mediterranean model bathymetry from US Navy DBDB1 $\left(1 / 60^{\circ}\right)$. The boxes define the sub-domains where diagnostics are calculated: Sardinia Channel and southern Tyrrhenian Sea (box A), Sicily Channel (box B), Tunisian shelf area (box C) and Libyan area (box D).

continental shelves are very wide and cover more than onethird of the spatial extent of the Sicily Channel. In the Gulf of Gabes, the bathymetry is shallower than $30 \mathrm{~m}$ for large stretches away from the coast.

The circulation in the CMED is characterized by a number of significant dynamical processes covering the full spectrum of temporal and spatial scales (Millot, 1999; Pinardi et al., 1997). The surface and subsurface flows are mainly driven by the large scale Mediterranean thermohaline circulation, and clearly by the momentum and buoyancy fluxes at the airsea interface. In addition there are wind-driven currents on the shelf due to remote storms; upwelling events off Sicily; sub-basin scale cyclonic and anticyclonic permanent gyres and small energetic mesoscale eddies with time scale shorter than 10 days (Manzella et al., 1988). The mesoscale structures under the influence of wind stress, topography and internal dynamical processes generate boundary currents and jets which can bifurcate, meander and grow then forming ring vortices and filament patterns interacting with the large scale flow fields (Lermusiaux, 1999; Lermusiaux and Robinson, 2001).

The high variability of the water masses properties and circulation characteristics has been largely investigated in the past years through hydrographical observations (Manzella and La Violette, 1990; Sammari et al., 1999), sub-surface currentmeters data (Astraldi et al., 1999; Vetrano et al., 2004;
Gasparini et al., 2005), Lagrangian drifters (Poulain and Zambianchi, 2007) and high resolution numerical simulations (Onken et al., 2003; Sorgente et al., 2003; Béranger et al., 2005). However, available observations are often characterized by poor spatial and temporal coverages, and are usually confined to the Italian seas while there is lack of observations over the Tunisian and Libyan continental shelves. Only few datasets have adequate temporal and spatial resolution to capture the mesoscale in local areas (Lermusiaux and Robinson, 2001).

Thus, numerical model simulations constitute an important tool to fill the observational gaps and to study the spatial and temporal ocean circulation variability. High resolution models, below $5 \mathrm{~km}$, were uncommonly used in the past mainly due to computational constraints. The computational issue poses the need to nest a hierarchy of successively embedded model domains, to downscale the large scale features to the coastal areas (Pinardi et al., 2003; Sorgente et al., 2003; Oddo et al., 2005). This methodology is found to be computationally efficient and sufficiently accurate to transmit information across the connecting lateral open boundaries without excessive distortion (Oddo and Pinardi, 2008).

The aim of this study is to investigate the mesoscale and the sub-basin scale dynamics in the CMED region, by mean of decomposition of the simulated flow fields into mean and eddy components, then giving an overall assessment of the spatial and temporal mesoscale variability in relation with atmospheric forcing and energy redistribution processes. The interest on mesoscale dynamic derives from the fact that eddies can potentially interact with the mean current and the bottom topography producing long term responses in the ocean circulation (Fernandez et al., 2005). The work has been done in the framework of the European COastal sea OPerational observing and forecasting system integrated project (ECOOP) funded by the European Commision's Sixth Framework Programme, which main aim was the construction of an European network of sea-forecasting systems, through the improvement (resolution, physics, data assimilation, distribution, etc.) of existing operational models.

In order to improve the investigation of the dynamics in the area, the model domain has been subdivided in four subregions, each one supposedly characterized by an homogeneous dynamics, as visible in Fig. 1: the Sardinia-Tyrrhenian area ( $\operatorname{area} A)$; the Sicily Channel (area B); the wide and shallow shelf area off Tunisia and Libya (area C); the wide slope area in front of Libya (area D).

This paper is structured as follows: in the Sect. 2 the main spatial and temporal scale variability of the surface circulation is briefly reviewed. Section 3 describes the characteristics of the model used, including the nesting method and the atmospheric coupling. In Sect. 4 the mean and eddy near surface kinetic energies, their seasonal cycle and structures are discussed, conclusions are presented in Sect. 5. 


\section{The physical regimes}

Three main spatial and temporal scales characterize the CMED: the large Mediterranean basin scale, including the thermohaline circulation; the sub-basin scale and the mesoscale. Each interacts with the others giving complex circulation patterns which arise from the multiple driving forces, strong topographic and coastal influences, and from internal dynamical processes (Robinson et al., 2001).

\subsection{The large scale circulation}

The main engine of the surface and subsurface large scale circulation is the remote forcing induced by the basin scale Mediterranean dynamics. The basin-scale thermohaline circulation in the Mediterranean Sea has been extensively studied in the past years by several authors through observational programs and numerical modelling studies (Zavatarelli and Mellor, 1995; Pinardi et al., 1997; Pinardi and Masetti, 2000; Béranger et al., 2005). The thermohaline circulation is antiestuarine (lagoonal) and it is driven mainly by the balance between the relatively fresh waters entering at the Gibraltar Strait and the negative fresh-water budgets over the whole Mediterranean basin. This is usually described as a zonal cell which involves the exchanges of water masses between the eastern and the western Mediterranean sub-basins with the transformation of the surface Atlantic Water (AW) in the Levantine Intermediate Water. Thus, the vertical structure consists of a two-layer flow with the surface AW moving eastward from the Gibraltar Strait and spreading from the Sicily Channel throughout the eastern Mediterranean subbasin as modified AW (Astraldi et al., 2002), and a salty Levantine outflow moving westward at intermediate depth. The zonal cell is connected with the "meridional" cells that are driven by the dense water mass formation processes occurring in the Gulf of Lions and Adriatic Sea (Schlitzer et al., 1991). In the Sicily Channel, the sill depth strongly modulates the exchange of these deep and intermediate waters between the two Mediterranean sub-basins.

In the western Mediterranean sub-basin the amplitude of the seasonal variability is large and involves intense currents and mesoscale variability while, in the eastern sub-basin, the inter-annual and seasonal variabilities have the same order of magnitude involving the characteristics of the deep and intermediate water masses and high mesoscale activity (Korres et al., 2000). Then, the CMED is a key area to monitor the thermohaline circulation and the corresponding hydrological trends (Astraldi et al., 1999, 2002) of the entire Mediterranean Sea.

\subsection{The sub-basin scale}

A schematic description of the seasonal variability of the subbasin scale surface circulation, including the new features described in this paper, is represented in Fig. 2, as derived from

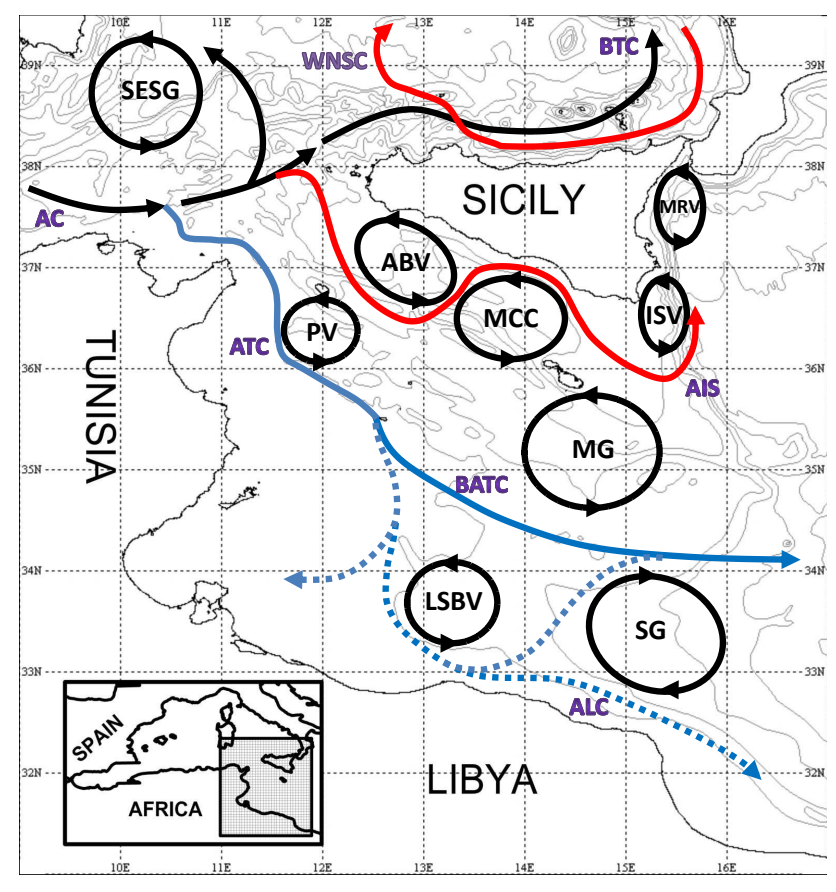

Fig. 2. Schematic surface circulation with cyclonic/anti-cyclonic features (modified from Lermusiaux and Robinson, 2001; Béranger et al., 2004 and Hamad et al., 2005) togheter with new features found in the present work. Acronyms are listed in Table 1. Permament features/paths are in black while seasonal are in red (summer) and in blue (winter). Continuous lines are for features from bibliography while dotted are for new ones.

Lermusiaux and Robinson (2001); Béranger et al. (2004) and Hamad et al. (2005). In the CMED the sub-basin scale features (jets, gyres and meanders) are part of the basin-wide circulation. The upper layer is occupied by the AW moving eastward as Algerian Current (AC), a coastal boundary current whose instability generates meanders few kilometres long and coastal eddies (Robinson et al., 2001). The cyclonic eddies are relatively superficial and short-lived, while the anticyclones last for weeks or months (Sammari et al., 1999; Astraldi et al., 2002). These mesoscale phenomena are disturbed by the South Eastern Sardinia Gyre (SESG, hereafter), a sub-basin scale wind curl driven cyclonic gyre centred approximately at $10^{\circ} \mathrm{E}-38.5^{\circ} \mathrm{N}$ (Artale et al., 1994) whose diameter varies between 200 and $300 \mathrm{~km}$.

Part of AC, after having crossed the Sardinia Channel, west of Sicily splits in two branches as a consequence of a topographic effect (Herbaut et al., 1998; Pierini and Rubino, 2001; Onken and Sellschopp, 2001; Onken et al., 2003; Béranger et al., 2004). The first branch directly flows into the Tyrrhenian Sea along the northern coast of Sicily (Astraldi et al., 1996), as Bifurcation Tyrrhenian Current (BTC), while the second turns southward into the Sicily Channel as a strong and narrow jet. Here it flows eastward in a twojet structure covering the upper $100 \mathrm{~m}$ with an associated 
Table 1. Acronyms and abbreviations.

\begin{tabular}{ll}
\hline ABV & Adventure Bank Vortex \\
AC & Algerian Current \\
AIS & Atlantic Ionian Stream \\
ALC & Atlantic Lybian Current \\
ATC & Atlantic Tunisian Current \\
AW & Atlantic Water \\
BATC & Bifurcation Atlantic Tunisian Current \\
BEC & Baroclinic Energy Conversion \\
BTC & Bifurcation Tyrrhenian Current \\
CMED & Central Mediterranean \\
EAPE & Eddy Available Potential Energy \\
ECOOP & European COastal sea OPerational \\
& observing and forecasting system \\
EKE & Eddie Kinetic Energy \\
ISV & Ionian Shelf break Vortex \\
LSBV & Libyan Shelf Break Vortex \\
MCC & Maltese Channel Crest \\
MG & Medina Gyre \\
MKE & Mean Kinetic Energy \\
MODIS & MODerate resolution Imaging \\
MRV & Spectroradiometer \\
POM & Messina Rise Vortex \\
PV & Princeton Ocean Model \\
SCRM & Sicily Channel Regional Model \\
SESG & South Eastern Sardinia Gyre \\
SG & Sidra Gyre \\
TKE & Total Kinetic Energy \\
WNSC & Westward Northern Sicilian Current \\
Wsw & Wind Stress Work \\
\hline &
\end{tabular}

salinity minimum: the Atlantic Tunisian Current (ATC) moving over the Tunisian continental slope, and the Atlantic Ionian Stream (AIS) along the southern coast of Sicily (Astraldi et al., 1996; Lermusiaux, 1999; Robinson et al., 1999; Lermusiaux and Robinson, 2001). It is worth to mention that the described bifurcation pattern is Gasparini et al. (2004) and by Gerin et al. (2009) from in situ data. They lightly different from what estimated by Astraldi et al. $(1999,2002)$, found that AW directly splits in three veins at the entrance of the Sicily Channel following separate tracks with the minimum of salinity along Tunisia. Vice versa, during the 1994-1996 AIS investigation by Robinson et al. (1999), the ATC/AIS bifurcation has not been observed but only the AIS was present with southerly branches in the Sicily Channel and Ionian Sea in a complicated meandering path. These changes in currents and water mass properties confirm the strong temporal variability of the area, where the mesoscale activity can be considered as an important source of interannual variability (Fernandez et al., 2005).

The main stream associated to the ATC flows eastward along the Tunisian and Libyan continental shelf break just south of Lampedusa or confined into the central part of the Sicily Channel (Manzella et al., 1988, 1990). The AIS constitutes a free jet energetic current mainly flowing eastward, along the southern coast of Sicily, as a typical waveform forcing upwelling on the Adventure Bank (western Sicilian shelf), especially during the summer when the current is strong. An important spatial variability exists and includes: shape, position and strength of permanent or quasipermanent sub-basin gyres and their unstable lobes, meanders patterns, bifurcation structures and strength of permanent jets, transient eddies and filaments (Robinson et al., 1999).

The sub-basin scale structures have seasonal amplitudes associated with the large wind stress variability (Pinardi and Navarra, 1993; Molcard et al., 2002). Recently, numerical studies (Onken et al., 2003; Sorgente et al., 2003; Béranger et al., 2004) and direct observations (Astraldi et al., 1996; 1999; Sammari et al., 1999; Poulain and Zambianchi, 2007) have been devoted to assess the seasonal characteristics of the surface circulation. Superimposed to such seasonal (subbasin) variability there is also a signal of interannual variability mainly due to the mesoscale and, in some measures, to lower frequency signals related to climate change (Olita et al., 2007).

\subsection{The mesoscale}

Mesoscale variability can be defined as the ensemble of flow fluctuations whose periods range from a few days to a few tenths of days. Many events are included in this broad definition, among which we are mostly interested in mesoscale variability associated to small vortices (i.e. mesoscale eddies). Its forcing mechanisms are mainly instabilities of the large-scale circulation, interactions between currents and bathymetry and the direct surface forcing. The interest in the CMED mesoscale dynamics comes from the hypothesis that fronts, jets, meanders and eddies can play an important role in the ocean as response to buoyancy forcing, winds and topographic gradients.

The horizontal scale of mesoscale eddies is related to the first baroclinic Rossby radius of deformation which, in the Sicily Channel, varies seasonally ranging from a minimum of about $8 \mathrm{~km}$ in January, to about $11 \mathrm{~km}$ during the period of stratification (Borzelli and Ligi, 1998). The radius almost vanishes in winter, over the Tunisian and Libyan shelf shallow area, due to a complete mixing of the water column.

In the CMED the mesoscale variability has been only marginally investigated. This is due to very high horizontal resolution required by numerical ocean models (computer resources) and/or a huge amount of in-situ data needed. An observational study was recently carried out by Poulain and Zambianchi (2007) analyzing more than 150 surfacedrifters in the period 1990-1999 to assess the spatial and seasonal variability of eddies and the mean surface kinetic energy. Previously, a similar study was realized by Lermusiaux 
(1999) and Lermusiaux and Robinson (2001) using a fourdimensional numerical primitive equation model and intensive in-situ data during August-September 1996, but limited to northern Sicily Channel. All of them found that the main features of dominant mesoscale variability are associated with five features: Adventure Bank Vortex, Maltese Channel Crest, Ionian Shelf break Vortex, Messina Rise Vortex and temperature and salinity fronts of the Ionian slope with their meanders and topographic wave patterns.

\section{Methods}

\subsection{Model design}

In order to reach an adequate resolution to model the mesoscale dynamics in the CMED, a nesting approach has been adopted. The Sicily Channel sub-Regional Model (SCRM, hereafter) has been embedded into the coarse basin model of the Mediterranean Forecasting System (MFS1671, hereafter; Tonani et al., 2008). This permits to produce a more detailed description of the circulation in the region, including some mesoscale components that cannot be resolved by the coarse model. SCRM is a free surface threedimensional primitive equation finite difference hydrodynamic model based on the Princeton Ocean Model (Blumberg and Mellor, 1987). It solves the equations of continuity, motion, conservation of temperature, salinity and assumes that the fluid is hydrostatic and the Boussinesq approximation is valid. The density is calculated by an adaptation of the UNESCO equation of state revised by Mellor (1991). The vertical mixing coefficients for momentum and tracers are calculated using the Mellor and Yamada (1982) turbulence closure scheme, while the horizontal viscosity terms are provided by the Smagorinsky parameterization (Smagorinsky, 1993).

SCRM is implemented between $9^{\circ} \mathrm{E}$ and $17.10^{\circ} \mathrm{E}$ and from $31.50^{\circ} \mathrm{N}$ to $39.50^{\circ} \mathrm{N}$ with a horizontal resolution of $1 / 32^{\circ}(\sim 3.5 \mathrm{~km})$. In the vertical it uses 30 sigma levels, with more coverage near the surface following a logarithmic distribution. The external time step is set to $4 \mathrm{~s}$, with an internal every $120 \mathrm{~s}$. The model bathymetry has been obtained from the US Navy Digital Bathymetric Data Base-DBDB1 at $1 / 60^{\circ}$ by bilinear interpolation into the model grid. The minimum depth is set to $5 \mathrm{~m}$. Additional smoothing is applied to reduce the sigma coordinate pressure gradient error (Mellor et al., 1994). The resulting model bathymetry is shown in Fig. 1.

The numerical system was run in free mode (i.e. without any data assimilation scheme) from January 2008 to December 2010 .

The model has been initialized at 00:00 on 1 January 2008 using dynamically balanced analyses fields from MFS1671 through an innovative tool based on the Variational Initialization and Forcing Platform (Auclair et al., 2000). This method is largely used in meteorological activities as drastically reduces the amplitude of the numerical transient processes, generally following the initialization phases for several days after the initialization. This method has been proven to drastically reduce the spin up time of the SCRM slave 5-days forecasts by Gabersék et al. (2007) to some few hours. On the light of such a result it has been used in the present experimental setup, permitting to diminish the spin up time problem.

Surface momentum and buoyancy fluxes are interactively computed by mean of dedicated bulk formulae developed and tested for the Mediterranean Sea in previous numerical exercises (Castellari et al., 1998; Tonani et al., 2008; Pinardi et al., 2003; Oddo et al., 2009). Fluxes computation takes into account model predicted sea surface temperature and the 6-h (00:00, 06:00, 12:00, 18:00 UTC) atmospheric parameters from European Centre for Medium range Weather Forecast operational analysis. The parameters are wind at $10 \mathrm{~m}$ a.s.l., air temperature at $2 \mathrm{~m}$ a.s.l., cloud cover, dew-point temperature and atmospheric pressure. These data have a horizontal resolution of $0.25^{\circ}$ and, successively, are mapped on the SCRM grid through bilinear interpolation and linearly interpolated in time at each model time step.

The surface boundary condition for momentum is:

$\left.K_{\mathrm{M}} \frac{\partial \boldsymbol{u}}{\partial z}\right|_{z=\eta}=\frac{\boldsymbol{\tau}}{\rho_{0}}$,

where $\tau$ is the wind stress vector, $K_{\mathrm{M}}$ is the vertical kinematic viscosity, $\rho_{0}=1025 \mathrm{~kg} \mathrm{~m}^{-3}$ is a reference density and $\eta$ is the free surface elevation. The wind stress components use a drag coefficient $C_{\mathrm{d}}=C_{\mathrm{d}}\left(T_{\mathrm{a}}, T, W\right)$ as function of the wind amplitude $(W)$, the air temperature $\left(T_{\mathrm{a}}\right)$ and the sea surface temperature predicted by the model $(T)$ following the polynomial approximation given by Hellerman and Rosenstein (1983). The surface boundary conditions for potential temperature take the classic form:

$\left.K_{\mathrm{H}} \frac{\partial T}{\partial z}\right|_{z=\eta}=\frac{Q_{\mathrm{T}}}{\rho_{0} C_{\mathrm{p}}}$,

where $Q_{\mathrm{T}}$ is the net heat flux, $C_{\mathrm{p}}\left(4186 \mathrm{~J} \mathrm{~kg}^{-1} \mathrm{~K}^{-1}\right)$ is the specific heat capacity of pure water at constant pressure and $K_{\mathrm{H}}$ is the vertical heat diffusivity. The net heat flux (Eq. 2) involves the balance between surface solar radiation $\left(Q_{\mathrm{S}}\right)$, the net long-wave radiation $\left(Q_{\mathrm{B}}\right)$, the latent $\left(Q_{\mathrm{E}}\right)$ and sensible $\left(Q_{\mathrm{H}}\right)$ heat fluxes. The heat flux components are calculated using the formula by Reed (1977) for the short wave radiation flux and that by Bignami et al. (1995) for long wave radiation. The turbulent components (latent and sensible heat fluxes) are computed by mean of the bulk aerodynamic formulae proposed by Kondo (1975).

For the salinity flux we consider the water balance:

$\left.K_{\mathrm{H}} \frac{\partial S}{\partial z}\right|_{z=\eta}=(E-P-R) \cdot S+C_{2}\left(S^{*}-S\right)$, 
$C_{2}=\Delta \sigma(1) \frac{H}{\alpha}$

where $E=Q_{\mathrm{E}} / L_{\mathrm{E}}$ is the evaporation rate interactively calculated, $L_{\mathrm{E}}$ the latent heat of evaporation, $P$ the monthly precipitation rate obtained from Legates and Willmott (1990), $R$ is the river runoff and $S$ is the surface model salinity at the first level. In our simulations the runoff $R$ is set to 0 because of the absence of rivers with significant discharge. The last term of Eq. (3) is the salinity flux correction and accounts for the imperfect knowledge of $E-P$ ( $P$ especially). $S^{*}$ is the monthly mean sea climatology surface salinity from Med6 dataset, that is based on the MEDATLAS dataset using the MODB (Mediterranean Oceanic Data Base) analyses techniques (Brasseur et al., 1996). $\Delta \sigma(1) H$ is the thickness of the surface layer, $\alpha$ is the relaxation time and $H$ the bottom depth. Value $C_{2}$ is equal to $0.7 \mathrm{~m} \mathrm{day}^{-1}$.

Lateral open boundary conditions are defined through a simple off-line one way nesting technique that represents an efficient way to downscale the model solutions from the basin-scale $(\sim 7 \mathrm{~km}$, the coarse model) to the sub-regional scale $(\sim 3.5 \mathrm{~km})$. It has been largely used in numerical weather predictions and recently in numerical oceanography to simulate the hydrodynamics of limited coastal areas (Drago et al., 2003; Sorgente et al., 2003; Zavatarelli and Pinardi, 2003; Oddo and Pinardi, 2008). The SCRM is nested at the lateral open boundaries with MFS1671 covering the whole Mediterranean Sea with a horizontal resolution of $1 / 16^{\circ}$ (Tonani et al., 2008; Oddo et al., 2009). The daily mean values of temperature, salinity, total velocity and elevation were transferred from the coarse spaced grid of MFS1671 to the finely spaced grid of the SCRM open boundaries through an off-line, one-way asynchronous nesting. The definition of the nested open boundary conditions is based on Sorgente et al. (2003).

\subsection{Energy analysis}

By taking in account previous experiences and in order to quantify the energy levels involved in the simulated circulation, in our work the flow field is divided into mean and eddy components. Generally, any velocity field $(u, v, w)$ can be divided into a time independent component $(U, V, W)$ and an eddy fluctuating part (time dependent, $\left.u^{\prime}, v^{\prime}, w^{\prime}\right)$ :

$u=U+u^{\prime} \quad v=V+v^{\prime} \quad w=W+w^{\prime}$

where the time independent part is obtained averaging temporally the full field over a given interval, $m$. For the three velocity components:

$U=\frac{1}{m} \sum_{j=1}^{m} u_{j}, \quad V=\frac{1}{m} \sum_{j=1}^{m} v_{j} \quad W=\frac{1}{m} \sum_{j=1}^{m} w_{j}$.

The $m$ term indicates the temporal scale (annual or monthly, as defined into the Sect. 4.1 and 4.2), j-th is the daily mean field and $u, v$ and $w$ are the zonal, meridional and vertical components of the total velocity respectively (as defined in Eq. 4).

The Total Kinetic Energy (TKE) per unit mass can be expressed as:

$\mathrm{TKE}=\frac{1}{2}\left(u^{2}+v^{2}\right)$,

substituting in the above equation the decomposition of the total velocity as defined in the Eq. (4), we obtain:

$\mathrm{TKE}=\frac{1}{2}\left(U^{2}+V^{2}\right)+\frac{1}{2}\left(u^{\prime 2}+v^{\prime 2}\right)+\left(U u^{\prime}+V v^{\prime}\right)$,

where the first term on the right hand side is the kinetic energy of mean flow per unit mass (MKE):

$\mathrm{MKE}=\frac{1}{2}\left(U^{2}+V^{2}\right)$,

while the second term is the kinetic energy per unit mass of the fluctuating flow, also called Eddy Kinetic Energy (EKE):

$\mathrm{EKE}=\frac{1}{2}\left(u^{\prime 2}+v^{\prime 2}\right)$.

The last term in the r.h.s of Eq. (6) is the first-order correlation term (Orlansky and Katzfey, 1991). The time average of TKE (Eq. 6) will contain only the first two terms (Eqs. 7 and 8), since the time mean of the third term vanishes. The logarithm of the ratio between the $\operatorname{EKE~(Eq.~8)~and~MKE~}$ (Eq. 7) defines the following parameter:

$\Phi=\log \left(\frac{\mathrm{EKE}}{\mathrm{MKE}}\right)$

which provides information on the energy distribution between the mean constant and fluctuating currents in the study area. In general, if $\Phi<0$ then MKE prevails on EKE, if $\Phi=0$ then EKE and MKE are of the same order, otherwise if $\Phi>0$ then EKE is larger than MKE. This last condition suggests that the energy of currents is dominated by the velocity fluctuating component.

In order to evaluate part of the sources of energy for the mesoscale in the study area, the Baroclinic Energy Conversion (BEC) has been evaluated. BEC (Orlansky and Katzfey, 1991) is defined as:

$\mathrm{BEC}=-\rho^{\prime} g w^{\prime}$

where $g$ is the gravitational acceleration, $w^{\prime}$ is the vertical component of the fluctuating velocity obtained applying Eq. (4), while $\rho^{\prime}$ arises from the decomposition of the instantaneous density $\rho(x, y, z, t)$ into a motionless part, a time independent component and a spatial and temporal varying component following the below equation:

$\rho(x, y, z, t)=\overline{\bar{\rho}}(z)+\bar{\rho}(x, y, z)+\rho^{\prime}(x, y, z, t)$.

BEC is the buoyancy work, which defines the conversion between the two form of eddy energies: Eddy Available Potential Energy (EAPE) and EKE (Lorenz, 1955; Pedlosky, 1987). 
We use the wind stress work to evaluate the relationship between TKE and the wind forcing. It is defined as:

$W s w=\boldsymbol{u} \cdot \boldsymbol{\tau}$

where $\boldsymbol{u}$ is the surface current vector and $\boldsymbol{\tau}$ the wind stress vector (Pedlosky, 1996; Zhai et al., 2007). The wind stress work (Wsw hereafter) represents the work done by the wind on the sea surface.

MKE and EKE have been vertically integrated and horizontally averaged over the four sub-regions previously defined and visible in Fig. 1 as follows:

$\vartheta(t)=\frac{1}{V} \int_{h 1}^{h 2} \int_{y 1}^{y 2} \int_{x 1}^{x 2} \vartheta(x, y, z, t) d x d y d z$.

The integration limits are the coordinates delimiting the horizontal sub-domain ( $x$ and $y$ ) and the vertical layers $(z)$, while the temporal scale $(t)$ is defined into the Sect. 4.1 and 4.2. Moreover the grid point, whose depth of the first sigma layer exceeds $1 \mathrm{~m}$, has been excluded (the deepest part of the Tyrrhenian Sea and of the east Ionian escarpment).

\subsection{Data}

In order to support results obtained by analyzing modelled fields, different sets of satellite measurements have been used.

Sea Level Anomaly data, used to support the observations of relatively large and offshore mesoscale eddies, are AVISO SSALTO/DUACS mapped and gridded weekly products with a spatial resolution of $1 / 8^{\circ}$ (http://www.aviso. oceanobs.com/).

Ocean-Color $1 \mathrm{~km}$ data are Level-2 (single swaths) acquired from MODerate resolution Imaging Spectroradiometer (MODIS) sensor on board of the AQUA mission and downloaded from the oceancolor web portal (http: //oceancolor.gsfc.nasa.gov/). The Level-2 MODIS data have been post-processed and re-projected through SEADAS ${ }^{\mathrm{TM}}$ software.

\section{Results and discussion}

The spatial variability of MKE, EKE and the ratio of EKE over MKE $(\Phi)$ simulated by SCRM on the period 20082010 are described on annual (Sect. 4.1) and monthly scale (Sect. 4.2), also comparing the simulated circulation with literature. In Sect. 4.3, the temporal variability of BEC has been analyzed, giving information about the source of energy for mesoscale induced by baroclinic instabilities.

The MKE field has been computed as defined in the Eq. (7), while EKE was obtained according to Eq. (8). Successively, MKE and EKE have been vertically integrated over the first $5 \mathrm{~m}$ depth and horizontally averaged over the whole area and in the four sub-regions as previously defined (Eq. 12). We integrated our results over the upper $5 \mathrm{~m}$ depth,
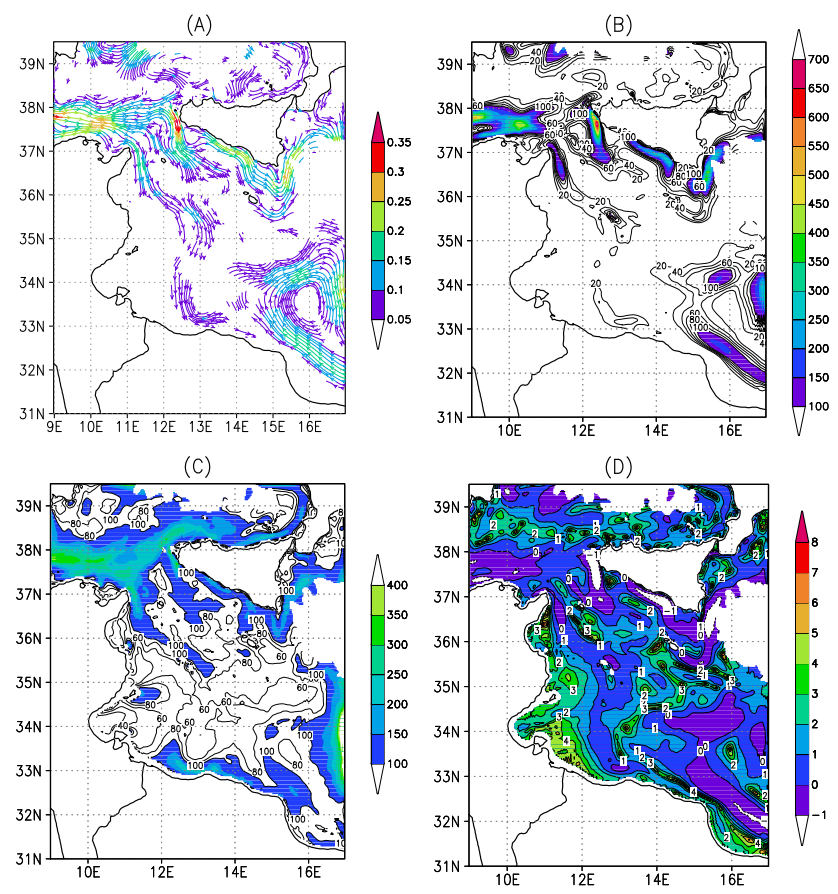

Fig. 3. Maps of mean flow (panel A, $\left[\mathrm{ms}^{-1}\right]$ ), MKE (panel B, $\left[\mathrm{cm}^{2} \mathrm{~s}^{-2}\right]$ ), EKE (panel $\mathbf{C},\left[\mathrm{cm}^{2} \mathrm{~s}^{-2}\right]$ ) and the logarithmic ratio EKE over MKE (panel D) averaged on the period 2008-2010 and vertically integrated from surface to $5 \mathrm{~m}$ depth. In panel (A) the minimum velocity current represented is $5 \mathrm{~cm} \mathrm{~s}^{-1}$. In panels (B) and (C) areas with MKE and EKE larger than $100 \mathrm{~cm}^{2} \mathrm{~s}^{-2}$ are shaded while the contour interval is $50 \mathrm{~cm}^{2} \mathrm{~s}^{-2}$. In panel (D) the contour interval is 1 .

that we consider representative for the surface layer. Our results have been qualitatively compared with EKE estimates derived from the drifters-based work of Poulain and Zambianchi (2007), which is the only observational reference available for the area.

\subsection{Mean circulation}

The annual mean field of the simulated surface circulation is obtained by averaging the daily mean velocity fields of SCRM as described in Eq. (5) where $m$ denotes the number of days over the simulated period (2008-2010). The model results are shown in Fig. 3, drawing the main characteristics of the basin and sub-basin mean surface circulation and confirming the results obtained from observations and previous studies (e.g. Zavatarelli and Mellor, 1995; Robinson et al., 2001; Astraldi et al., 2001, 2002; Onken et al., 2003; Béranger et al., 2004).

The analysis of the mean circulation (Fig. 3a) shows the AC flowing eastward along the northern Tunisian shelf with MKE over $400 \mathrm{~cm}^{2} \mathrm{~s}^{-2}$ (Fig. 3b) on the northern Tunisian shelf break and the Skerki Bank. AC splits in the AIS and the ATC while BTC doesn't clearly appear in the mean flow. 
The AIS flows between Pantelleria and the southern Sicilian coast, then north of Malta and intrudes into the deep Ionian Sea after the overshooting along the eastern Sicilian coast, as described by Lermusiaux (1999) and Sorgente et al. (2003). High values of MKE (Fig. 3b) above $500 \mathrm{~cm}^{2} \mathrm{~s}^{-2}$ are found over the Adventure Bank, along the southern Sicilian coast and along the Ionian shelf break. Apart the MKE patches over the Adventure Bank that could be overestimated because of an relatively smooth bathymetry, the simulated MKE distribution is generally in agreement with the paths detected by Poulain and Zambianchi (2007).

In the central part of the Sicily Channel the MKE appears rather weak. The ATC flows southward along the Tunisian coast as a relatively strong current decreasing progressively its velocity south-eastward. It flows approximately following the $200 \mathrm{~m}$ isobaths until Libya with MKE below $50 \mathrm{~cm}^{2} \mathrm{~s}^{-2}$ between $12^{\circ} \mathrm{E}$ and $14^{\circ} \mathrm{E}$. This limited feature is also visible in Fig. 3a and in full agreement with drifter observations. We call this narrow current as Atlantic Libyan Current (ALC, hereafter) which can be considered as the eastward extension of ATC along the Libyan coast (Gasparini et al., 2008; Poulain and Zambianchi, 2007). A further dominant feature is the Sidra Gyre, previously mentioned by several authors (Korres et al., 2000; Sorgente et al., 2003; Fernandez et al., 2005; Tonani et al., 2008), a sub-basin permanent anti-cyclonic structure centred at about $33.5^{\circ} \mathrm{N}$ and $16^{\circ} \mathrm{E}$ and detected also by drifter trajectories (Poulain and Zambianchi, 2007). Its diameter is about $150-200 \mathrm{~km}$. It strongly interacts with the ALC, pushing the modified AW toward the Libyan coast in a narrow stream. The Sidra Gyre appears as the main dynamical mechanism that influences the outflow of AW outside the Sicily Channel, having a seasonal and interannual variability, as stated by Gerin et al. (2009) and Ciappa (2009). It also controls the inflow of warm and salty Ionian Surface Water from the eastern side of the Libyan shelf through its southern arm. This feature is represented by a westward flow characterized by values of MKE of about $100 \mathrm{~cm}^{2} \mathrm{~s}^{-2}$ (Fig. 3b).

The EKE map (Fig. 3c), which includes the variability due to small scale eddies, to sporadic wind-driven current events and also to the seasonal modulation of the surface circulation with internal energy redistribution processes, shows almost the same spatial patterns observed for MKE, suggesting a strong variability associated to the intensity of the currents with larger values of TKE. Values of EKE less than $50 \mathrm{~cm}^{2} \mathrm{~s}^{-2}$ are found at the deepest part of the Sicily Channel, below Malta. Vice-versa, large fluctuations over $100 \mathrm{~cm}^{2} \mathrm{~s}^{-2}$ are found in regions with strong currents, such as along the northern Tunisian shelf break (the AC), with the highest values $\left(>350 \mathrm{~cm}^{2} \mathrm{~s}^{-2}\right)$ over the Skerki Bank, westward and along the northern Sicilian coast. This succession identifies the path of BTC, which does not clearly appear in the mean flow. Downstream the Sicily Channel, high values are found between Malta and Sicily and at significant topographic gradients of the Ionian escarpment. Isolated struc- tures also appear along the Libyan coast between $12^{\circ} \mathrm{E}$ and $14^{\circ} \mathrm{E}$. Most of them have been confirmed by the above mentioned drifter observations, even if the model underestimates the energy content of these structures. This underestimate for MKE and EKE could be due to the different sampling periods, 1990-1999 for the drifter-based study and 20082010 for the model, or to the unevenly sampling accomplished through the drifters. Obviously, this disagreement in term of values could also be due to the other factors like the low resolution atmospheric forcing, an inadequate modelled viscosity-diffusivity or an insufficient vertical resolution of the model. In any case our model results indicate that the mean EKE, averaged over the whole domain, is about $90 \mathrm{~cm}^{2} \mathrm{~s}^{-2}$, three times MKE.

The energy ratio between the mean constant and fluctuating currents is represented by the parameter $\Phi$ (Eq. 9) which compares the levels of MKE and EKE (Fig. 3d). The values with $\Phi<0$ identify the main stream currents where the mean flow kinetic energy is larger than EKE, as for AC and AIS. The areas where MKE and EKE are roughly similar $(\Phi=0)$ are identified by the paths of ATC with its bifurcations, ALC and the Sidra Gyre. Vice versa the EKE can be up about three times larger in logarithmic term than $\operatorname{MKE}(\Phi>1)$ into the deepest part of the Sardinia Channel and Tyrrhenian Sea, over the major part of the Tunisian shelf as isolated features in the Sicily Channel, between ATC and AIS, and between Malta and Libya westward of the Sidra Gyre where the mean flow is really weak.

\subsection{Seasonal variability of kinetic energy and surface circulation}

In order to analyze the MKE and EKE components of the kinetic energy budgets, the simulated daily mean velocity fields of SCRM have been averaged on monthly basis over the period 2008-2010 computed as in Eq. (4) where m denotes the number of days for each month. The monthly averaged time series of TKE, MKE, EKE and the Wsw are shown in Fig. 4. The TKE (Fig. 4a), sum of MKE and EKE, has a seasonal cycle with values larger than $150 \mathrm{~cm}^{2} \mathrm{~s}^{-2}$ between November and March. The EKE, always larger than MKE (Fig. 4b), dominates such a TKE seasonality following a similar cycle. Finally the MKE shows a smaller seasonal variability with an opposition phase period (EKE decreases while MKE increases) between May and July (relative maximum). The winter peaks of MKE and EKE appear to be related to the Wsw (Fig. 4c), which has values over about $0.3 \mathrm{~N} \mathrm{~m}^{-1} \mathrm{~s}^{-1}$ from November to March. From April to October the Wsw is weak and remains approximately constant, not exceeding $0.1 \mathrm{~N} \mathrm{~m}^{-1} \mathrm{~s}^{-1}$. On the contrary, the summer peak (in July) of MKE is not directly related to the Wsw but it is probably related to the internal dynamics associated with the presence and action of intense summer current systems as AIS and the Westward Northern Sicilian Current, introduced in Sect. 4.2.1. 
(A)

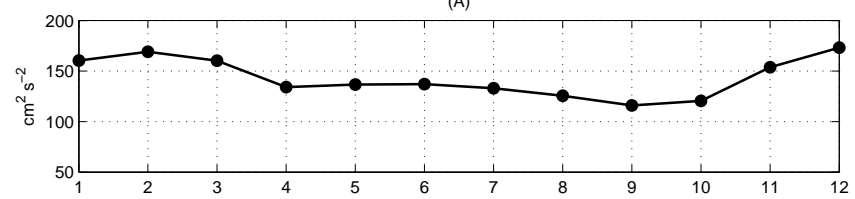

(B)
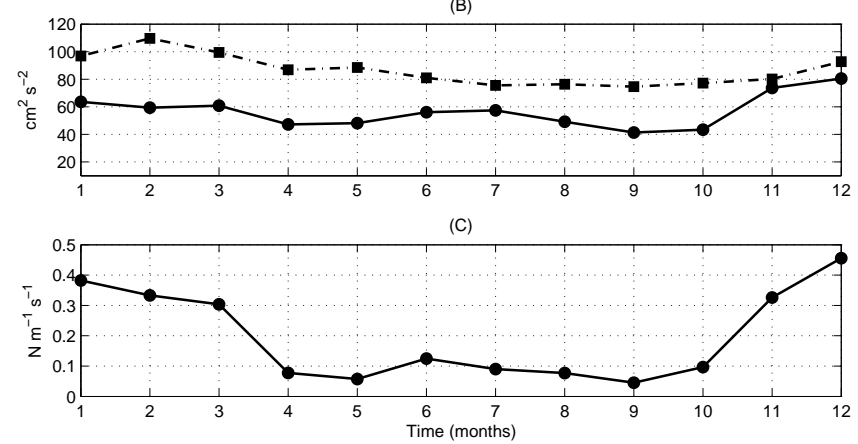

Fig. 4. Time series of: monthly mean TKE (panel $\mathbf{A},\left[\mathrm{cm}^{2} \mathrm{~s}^{-2}\right]$ ); MKE - solid line - and EKE - dashed line - (panel B, $\left.\left[\mathrm{cm}^{2} \mathrm{~s}^{-2}\right]\right)$; Wsw (panel $\mathbf{C},\left[\mathrm{N} \mathrm{m}^{-1} \mathrm{~s}^{-1}\right]$ ). All time series has been averaged overall the model domain, vertically integrated from surface to $5 \mathrm{~m}$ depth and on the period 2008-2010.

The same analyses has been applied in each of the four sub-regions in which the whole domain has been divided (Fig. 1) in order to quantify possible differences in the spatial energy distribution and ratio (MKE, EKE and $\Phi$ ).

\subsubsection{The Sardinia-Tyrrhenian sub-region}

The Sardinia-Tyrrhenian sub-region (A in Fig. 1) appears as the most energetic (Fig. 5). EKE is always larger than MKE apart in November and December. On annual mean the contribution of EKE to TKE is about $57 \%$ on annual basis. The EKE shows a seasonal cycle with a maximum value in February $\left(\sim 160 \mathrm{~cm}^{2} \mathrm{~s}^{-2}\right)$ and minimum in September $\left(\sim 80 \mathrm{~cm}^{2} \mathrm{~s}^{-2}\right)$, while MKE shows values over $100 \mathrm{~cm}^{2} \mathrm{~s}^{-2}$ from November to January then progressively decreasing towards its minimum values in April and September $\left(\sim 60 \mathrm{~cm}^{2} \mathrm{~s}^{-2}\right)$ and a relative maximum in July $\left(\sim 80 \mathrm{~cm}^{2} \mathrm{~s}^{-2}\right)$. The Wsw is characterized by two forcing regimes: from November to March it is always over $0.5 \mathrm{~N} \mathrm{~m}^{-1} \mathrm{~s}^{-1}$, reaching its absolute maximum in December $\left(0.8 \mathrm{~N} \mathrm{~m}^{-1} \mathrm{~s}^{-1}\right)$, while from April to October it doesn't exceed $0.25 \mathrm{~N} \mathrm{~m}^{-1} \mathrm{~s}^{-1}$. Then the small MKE summer peak in July appears not directly related to the wind stress work. The comparison between EKE and MKE, represented by the parameter $\Phi$ (see Eq. 9), shows a positive signal $(\Phi>0)$ apart in November and December. This means that the surface dynamics is usually dominated by the velocity fluctuating component with its maximum in April $(\Phi \sim 0.8)$, while in November the mean flow on the velocity fluctuating component prevails $(\Phi<0)$. We would underline the significance of such a ratio: the $\Phi$ parameter informs when/where EKE is larger than MKE or, in other words, when mesoscale activity is stronger than the mean flow then neglecting the absolute value of EKE.

The horizontal distribution of $\Phi$ in November (Fig. 6a) shows MKE prevailing on $\operatorname{EKE}(\Phi<0)$ in correspondence of $\mathrm{AC}$ and BTC paths. The mean flow of such features appear as coastal boundary currents flowing, respectively, along the northern Tunisian coast (AC) and along the northern Sicilian shelf break (BTC), in agreement with the literature (Astraldi et al., 1996; Molcard et al., 2002). Such a spatial feature is mainly due to the MKE field (not shown) reaching values over $800 \mathrm{~cm}^{2} \mathrm{~s}^{-2}$ along the AC path that are compatible with speed currents of about $40 \mathrm{~cm} \mathrm{~s}^{-1}$ then decreasing eastward. Lower values $\left(<200 \mathrm{~cm}^{2} \mathrm{~s}^{-2}\right)$ occur along the BTC path. The EKE is largely higher than MKE $(\Phi>1)$, especially in deep areas of the Sardinia Channel where the energy of the currents is dominated by the fluctuating component, whose monthly mean reaches its maximum in February (Fig. 5b). The EKE field, with the current mean flow overlapped, is represented in Fig. 6b. Values over $300 \mathrm{~cm}^{2} \mathrm{~s}^{-2}$ are found along AC and BTC paths, increasing to the same order than MKE (not shown). Isolated patches of EKE show very high values $\left(>400 \mathrm{~cm}^{2} \mathrm{~s}^{-2}\right)$ on the northern Tunisian shelf and along the northern Sicilian coast. EKE maxima are always associated with high energetic flows like the AC and BTC. BTC strength appears mainly related to the eastward flow at the Sardinia-Tunisia section (Fig. 7) and, secondly, to the atmospheric forcing (Fig. 5e). Vice-versa, the EKE prevails where there is not a clear mean flow, suggesting that the EKE signal would be due to instabilities generated along the currents boundaries.

Toward the summer months AC and BTC progressively decrease, in agreement with Astraldi et al. (2002) and Sorgente et al. (2003), but the temporal evolution of MKE (Fig. 5c) shows a small increase on July. Here the model results show the mean surface circulation dominated by the meandering of a weaker AC, some split currents, cyclonic and anti-cyclonic eddies, the SESG and a westward coastal current flowing along the northern Sicilian coast (Fig. 8). SESG replaces part of the BTC path in summer and appears particularly active in term of MKE from June to September (not shown). This coastal current seems to be part of a large anticyclonic gyre located on the southern side of the Tyrrhenian Sea. Actually there are no bibliographic indications on the existence of this feature which would deserve a more detailed study. We refer to this as Westward Northern Sicilian Current (WNSC, hereafter). It appears more stable and stronger than AC justifying the July increase of MKE described above.

\subsubsection{The Sicily sub-region}

The Sicily sub-region (B in Fig. 1) appears less energetic than the previous one, with a contribution of EKE to TKE of about $55 \%$ on annual basis (Fig. 5). The monthly time series of MKE and EKE have almost comparable values, except in 

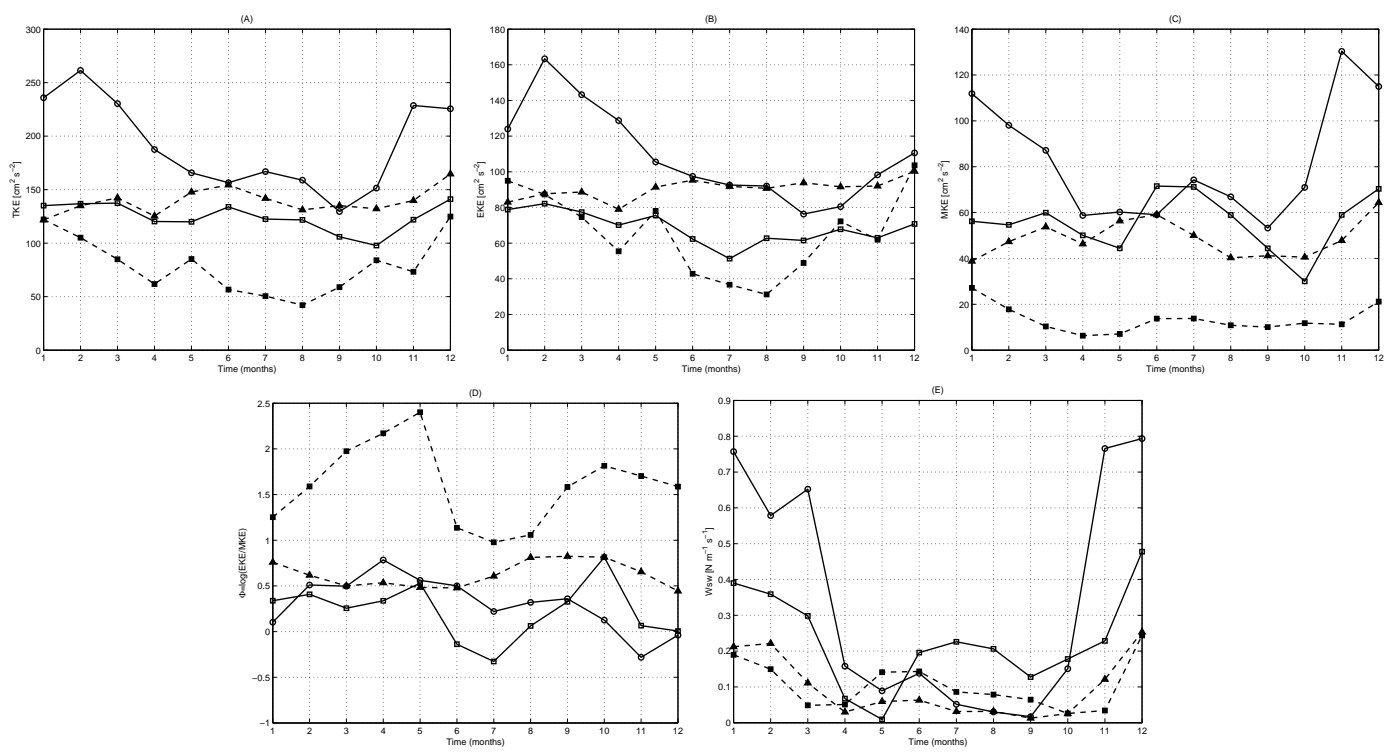

Fig. 5. Time series of: TKE (A), EKE (B), MKE (C), $\Phi$ (D), Wsw (E); all time series have been averaged for the Sardinia-Tyrrhenian sub-region (continous-line, empty circle), Sicily sub-region (continuos-line, empty square), Tunisian sub-region (dashed-line, full square), Lybian sub-region (dashed-line, full triangle), vertically integrated from surface to $5 \mathrm{~m}$ depth and on the period 2008-2010.

(A)

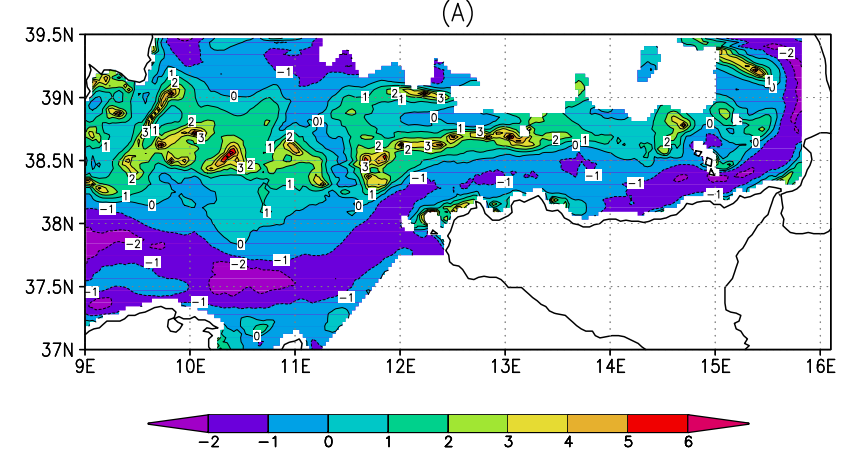

(B)

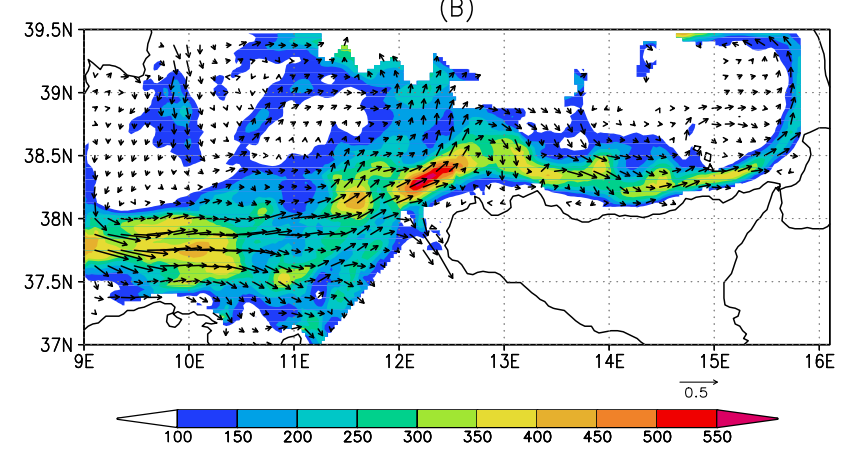

Fig. 6. Monthly mean map of Sardinia - Tyrrhenian sub-region for $\Phi$ in November (panel $\mathbf{A}$ ) and of the mean flow overlapped to EKE (panel $\mathbf{B},\left[\mathrm{m} \mathrm{s}^{-1}\right]$ and $\left[\mathrm{cm}^{2} \mathrm{~s}^{-2}\right]$ respectively) in February. Areas with EKE higher than $100 \mathrm{~cm}^{2} \mathrm{~s}^{-2}$ are shaded

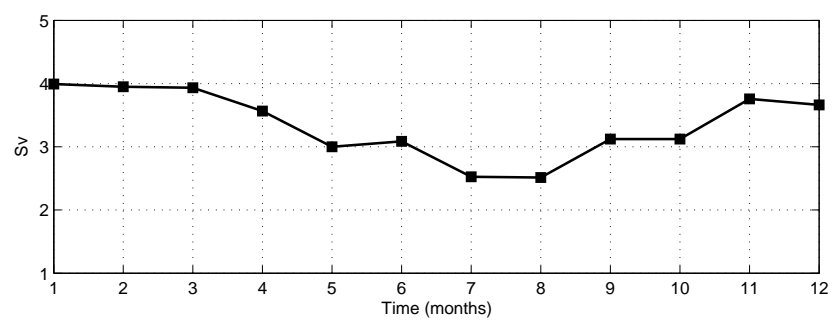

Fig. 7. Monthly mean time series of the eastward flow $[\mathrm{Sv}]$ at the section Sardinia-Tunisia computed averaging the daily data from January 2008 to December 2010

October, and do not show a clear seasonal cycle. EKE levels are always larger than MKE apart in June, July and December, ranging approximately between 50 and $80 \mathrm{~cm}^{2} \mathrm{~s}^{-2}$. The MKE series show a temporal evolution characterized by a relative maximum in June and July $\left(\sim 60 \mathrm{~cm}^{2} \mathrm{~s}^{-2}\right)$ and an absolute maximum in December $\left(\sim 70 \mathrm{~cm}^{2} \mathrm{~s}^{-2}\right)$. The Wsw is characterized by lower values than in the Sardinia - Tyrrhenian sub-region but with a similar temporal evolution. The comparison between EKE and MKE given by $\Phi$ shows the former prevailing $(\Phi>0)$ especially in October, slightly negative in June and July, while in August, November and December the two kinetic components are almost equal $(\Phi \sim 0)$. The horizontal distribution of $\Phi$ in December (Fig. 9a) shows MKE prevailing on EKE $(\Phi<0)$ in correspondence of ATC and AIS. On the contrary the EKE exceeds the MKE $(\Phi>0)$ up to three times (in logarithmic term) into the deepest part of the channel between the two currents systems ATC and AIS. The horizontal distribution of EKE, with the mean current 


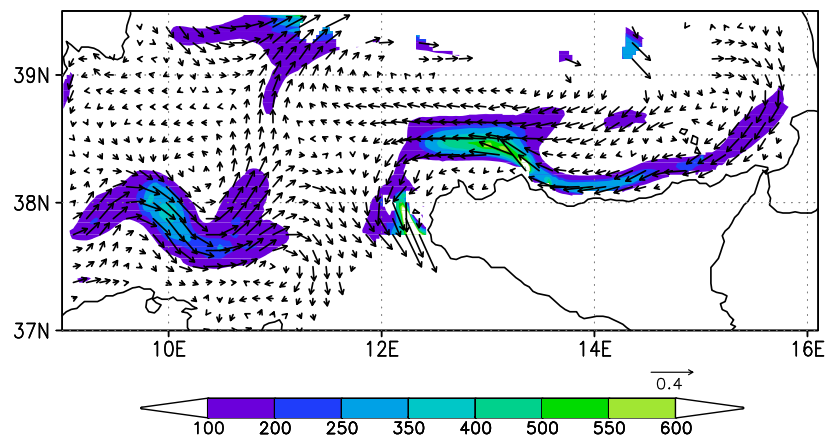

Fig. 8. Monthly mean map for the Sardinia-Tyrrhenian sub-region of MKE $\left[\mathrm{cm}^{2} \mathrm{~s}^{-2}\right]$ in July averaged on the period 2008-2010 and vertically integrated from surface to $5 \mathrm{~m}$ depth. It puts in evidence the presence of the WNSC flowing along the northern Sicilian coast.
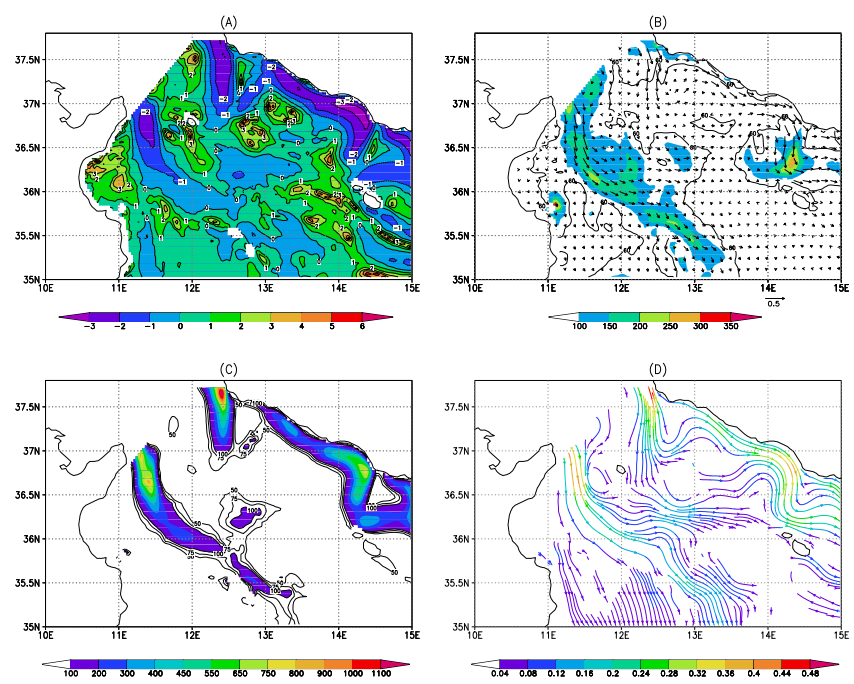

Fig. 9. December monthly map in the Sicily Channel sub-region for $\Phi$ (panel $\mathbf{A}$ ), mean flow [ $\mathrm{m} \mathrm{s}^{-1}$ ] overlapped to EKE (panel $\mathbf{B}$, $\left[\mathrm{cm}^{2} \mathrm{~s}^{-2}\right]$ ) and MKE (panel $\mathbf{C},\left[\mathrm{cm}^{2} \mathrm{~s}^{-2}\right]$ ) and streamlines of the mean flow $\left(\mathbf{D},\left[\mathrm{m} \mathrm{s}^{-1}\right]\right)$. Areas with MKE and EKE higher than $100 \mathrm{~cm}^{2} \mathrm{~s}^{-2}$ are shaded.

flow superimposed, is presented in (Fig. 9b). This figure shows the ATC as an offshore boundary current rather variable $\left(E K E>150 \mathrm{~cm}^{2} \mathrm{~s}^{-2}\right)$ and intense, which progressively decreases southeastward along Tunisia. It is visible from October to May and reaches its maximum intensity in December (not shown). Here the AIS is represented as a coastal current, less variable $\left(\mathrm{EKE}<100 \mathrm{~cm}^{2} \mathrm{~s}^{-2}\right)$ than ATC, flowing eastward confined along the southern Sicilian coast in agreement with literature e.g. Ciappa (2009). In Fig. 9c high values of $\operatorname{MKE}\left(>800 \mathrm{~cm}^{2} \mathrm{~s}^{-2}\right)$ are isolated patches on the Adventure Bank, in correspondence of the Maltese Channel Crest and along the ATC path downstream Cape Bon. A contribution to the increase of the MKE along the ATC path is given by a small cyclonic vortex downstream the island of Pantelle-
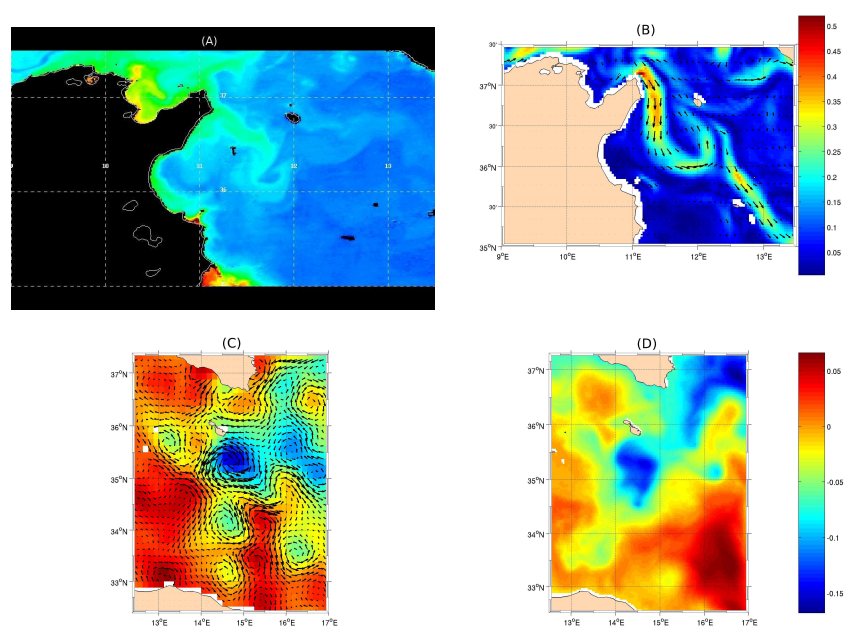

Fig. 10. Panel (A): MODIS level-2 K490 image at 11 May 2009 where the Pantelleria Vortex is clearly defined south west of the Pantelleria island; panel (B): simulated surface velocity field for the same day where the depression corresponding to the vortex is clearly shown in the same position of the observation; panel $(\mathbf{C})$ : Sea Level Anomaly [m] map at 30 January 2009 where the Medina Gyre is evident as a wide depression (cyclonic) south of Malta; panel (D): the Medina Gyre at 1 February 2009 well identified in the simulated surface elevation $[\mathrm{m}]$.

ria (Fig. 9d) that constrains the core of the AW towards the Tunisian slope increasing its velocity. This mesoscale feature appears to be connected to ATC path and is located approximately at $11.75^{\circ} \mathrm{E}-36.6^{\circ} \mathrm{N}$. We named this feature Pantelleria Vortex (PV, hereafter). If particularly energetic, $\mathrm{PV}$ can induce a recirculation of AW into the Sicily Channel (not shown). Actually there are no bibliographic references on the existence of this feature from oceanographic surveys but PV is clearly identified by Ocean Color images (MODIS AQUA level 2 data). Figs. 10a and $b$ show respectively MODIS K490 level 2 (reflectance at $490 \mathrm{~nm}$ wavelength, which is used in this case as passive tracer for dynamical features) and the simulated free surface elevation field at 11 May 2010 in the PV area. The PV is well identified and defined both in the simulated and observational satellite fields.

The monthly mean flow prevails on the velocity fluctuating component in July (Fig. 5c) due to an increase of MKE, with a slight decrease of EKE (Fig. 5b), mainly induced by the AIS. Here the surface circulation (not shown) is represented by an intense AIS which appears rather variable (EKE $\sim 100 \mathrm{~cm}^{2} \mathrm{~s}^{-2}$ ). It reaches the largest values in the western side of the Adventure Bank Vortex (MKE $>800 \mathrm{~cm}^{2} \mathrm{~s}^{-2}$ ) progressively decreasing south-eastward. Along its path the mean flow prevails on the fluctuating component $(\Phi<0)$ up twice, while the south-western side of the domain shows large portions of the area dominated by the fluctuating component (not shown). The ATC appears weak or not present at all, in agreement with observations (Manzella et al., 1988, 

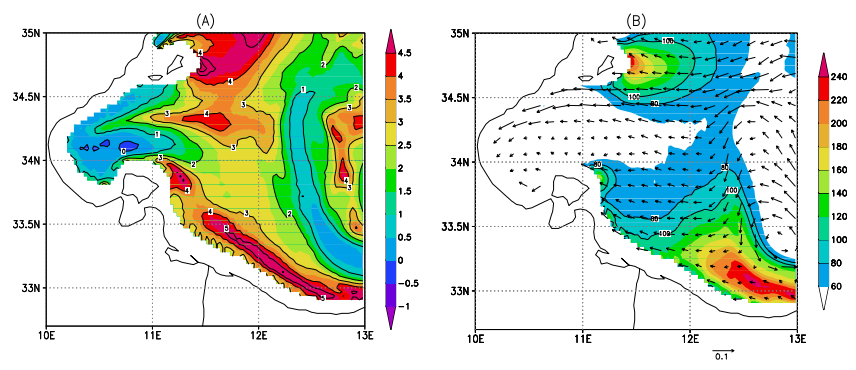

Fig. 11. Monthly mean map for the Tunisian sub-region in May of $\Phi$ (panel A) and EKE (panel B, $\left[\mathrm{cm}^{2} \mathrm{~s}^{-2}\right]$, with mean flow $\left[\mathrm{m} \mathrm{s}^{-1}\right]$ superimposed) averaged on the period 2008-2010 and vertically integrated from surface to $5 \mathrm{~m}$ depth. Area with EKE larger than $60 \mathrm{~cm}^{2} \mathrm{~s}^{-2}$ are shaded.

1990) and numerical simulations (Sorgente et al., 2003; Béranger et al., 2004).

\subsubsection{The Tunisian - Libyan sub-region}

The Tunisian-Libyan sub-region ( $\mathrm{C}$ in Fig. 1 ) is a very shallow area with maximum depths of about $250 \mathrm{~m}$ at its easternmost limit. Here the MKE is quite low while the monthly EKE values are up to four times higher than MKE (Fig. 5b, c) in logarithmic scale. The EKE contribution to TKE is therefore dominant, reaching about $83 \%$ on annual basis. This means that this area is almost completely controlled by the fluctuating currents. The wind stress (Fig. 5e) is very weak and does not seem to be the primary source of energy in this region. The EKE-MKE ratio (Fig. 5d) shows an absolute maximum in May and a relative maximum in October while the absolute minimum is in July.

The horizontal distribution of $\Phi$ for May (Fig. 11a) shows the whole sub-domain roughly dominated by the fluctuating component, with the highest ratio $(\Phi>3)$ between Libya and the $100 \mathrm{~m}$ isobath. This signal propagates northwestward, gradually decreasing. EKE and MKE are almost of the same order $(\Phi \sim 0)$ along the Libyan shelf break where the mean flow is represented by a weak current bounded by a cyclonic vortex approximately located at $12.8^{\circ} \mathrm{E}-33.4^{\circ} \mathrm{N}$ (Fig. 11b) that we call Libyan Shelf Break Vortex (LSBV in Fig. 2). LSBV appears as a permanent feature of the surface circulation from May to October whose position and strength contribute to frequent reversals of the coastal currents along the Libyan coast, together with the atmospheric forcing. This is shown by the high EKE values $\left(>200 \mathrm{~cm}^{2} \mathrm{~s}^{-2}\right)$ between the southern side of the cyclonic vortex and the Libyan coast. Another interesting feature is represented by the western current coming from the center of the Sicily Channel towards the Gulf of Gabes. It appears weak (MKE $<10 \mathrm{~cm}^{2} \mathrm{~s}^{-2}$ ) and particularly evident in the model results from April to July under the forcing of easterly winds (not shown). This feature has been also observed by Poulain and Zambianchi (2007).
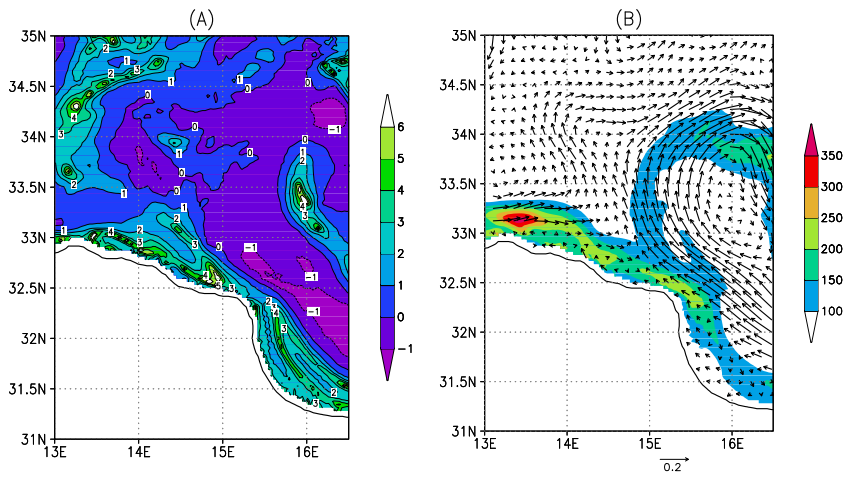

Fig. 12. Monthly mean map for the Libyan sub-region in October of $\Phi$ (panel $\mathbf{A}$ ) and EKE (panel $\mathbf{B},\left[\mathrm{cm}^{2} \mathrm{~s}^{-2}\right]$ ) superimposed on the mean flow $\left[\mathrm{m} \mathrm{s}^{-1}\right]$ averaged on the period 2008-2010 and vertically integrated from surface to $5 \mathrm{~m}$ depth. Area with EKE larger than $100 \mathrm{~cm}^{2} \mathrm{~s}^{-2}$ are shaded.

\subsubsection{The Libyan sub-region}

The Libyan sub-region (D in Fig. 1) has an important role in the thermohaline circulation of the Mediterranean Sea, as underlined by Gasparini et al. (2008). In this sub-region the contribution of EKE to TKE is about $65 \%$ on annual basis. The MKE and EKE signals are in phase without a clear seasonal cycle (Fig. 5). Their kinetic energies are found high through the whole year and particularly in June. It is difficult, even visually, to find any relation with the Wsw (Fig. 5e), which seems uncoupled from EKE. The Wsw is more intense than in the Tunisia - Libya sub-region and weaker than in the Sicily Channel and in the Sardinia - Tyrrhenian sub-region. The logarithm of EKE-MKE ratio (Fig. 5d) is always positive $(\Phi>0)$ with maximum values from August to October and minimum from March to June $(\Phi \sim 0.5)$.

The horizontal distribution of $\Phi$ in October (Fig. 12a) shows EKE prevailing on MKE $(\Phi>0)$ over bathymetries shallower than $200 \mathrm{~m}$ depth. Here EKE reaches and overpasses $200 \mathrm{~cm}^{2} \mathrm{~s}^{-2}$ (Fig. 12b). This obviously indicates a highly variable zone with current reversals induced by the temporal variability of the atmospheric forcing and the ALC, whose existence is supported by CTD observations (Gasparini et al., 2008) and drifting measurements (Poulain and Zambianchi, 2007). Its width and flow advection along the Libyan shelf seems to be connected to the strength of the ATC and to the position and horizontal extension of the Sidra Gyre. Our results indicate the existence of ALC especially from November to April (not shown). EKE and MKE are almost of the same order (see Fig. 12q, $\Phi=0.0$ ) offshore Libya where the mean flow is represented by the western side of the Sidra Gyre, approximately centered at about $15.9^{\circ} \mathrm{E}-33.5^{\circ} \mathrm{N}$ (see in Fig. 12b). This feature, observed also by satellite image (Ciappa, 2009), appears as a permanent structure of the surface circulation and its temporal and spatial variability would deserve a deeper study. Its main impact on the surface 


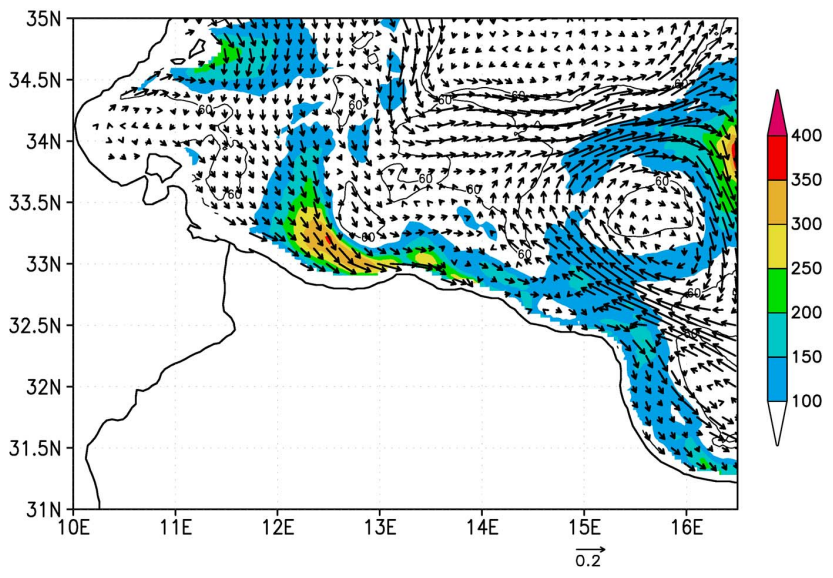

Fig. 13. Monthly mean map of EKE superimposed on the mean flow $\left[\mathrm{m} \mathrm{s}^{-1}\right]$ in December over the Tunisian and Libyan areas.

circulation is the advection of warm and salty Ionian surface water, coming from the eastern side of the Libyan shelf, through a wide and weaker (MKE $<120 \mathrm{~cm}^{2} \mathrm{~s}^{-2}$ ) surface current flowing northwestward offshore Libya (not shown). The presence of this dense vein along the Libyan continental margin has been also detected by Gasparini et al. (2008) during a cruise in 2006. The contrast between the Ionian surface water and the modified AW, advected by the ALC, can induce the formation of strong density gradients along the Libyan shelf break, as shown in the next section.

In this sub-region model results also show some unfamiliar features like the splitting of ATC, approximately at $34^{\circ} \mathrm{N}$ and $14^{\circ} \mathrm{E}$, that bifurcates in an eastward and a southward component (Fig. 13). The eastward current mainly flows into the Ionian Sea supported by the anti-cyclonic circulation (the Sidra Gyre). We named this branch as the Bifurcation Atlantic Tunisian Current (BATC) represented by a wide, weak (MKE $<150 \mathrm{~cm}^{2} \mathrm{~s}^{-2}$ ) and stable surface current $\left(\mathrm{EKE} \sim 50 \mathrm{~cm}^{2} \mathrm{~s}^{-2}\right.$ ) particularly evident from November to April (not shown). Unfortunately the knowledge of the circulation in this area is rather poor due to a lack of observational data, as also recently underlined by Gasparini et al. (2008). Future investigations will be addressed to evaluate the favorable conditions for the splitting of the ATC and on what influences on its spatial and temporal variability.

\subsection{Baroclinic Energy Conversion}

The variability of the EKE of the circulation in the CMED has been depicted in the previous sections. In order to evaluate and identify the part of the mesoscale activity due to baroclinic instabilities, the spatial and temporal variability of the BEC (Eq. 10) has been analyzed in the model domain and in each sub-region. The maps of BEC permit to represent the spatial distribution of the baroclinic instabilities at monthly scale.
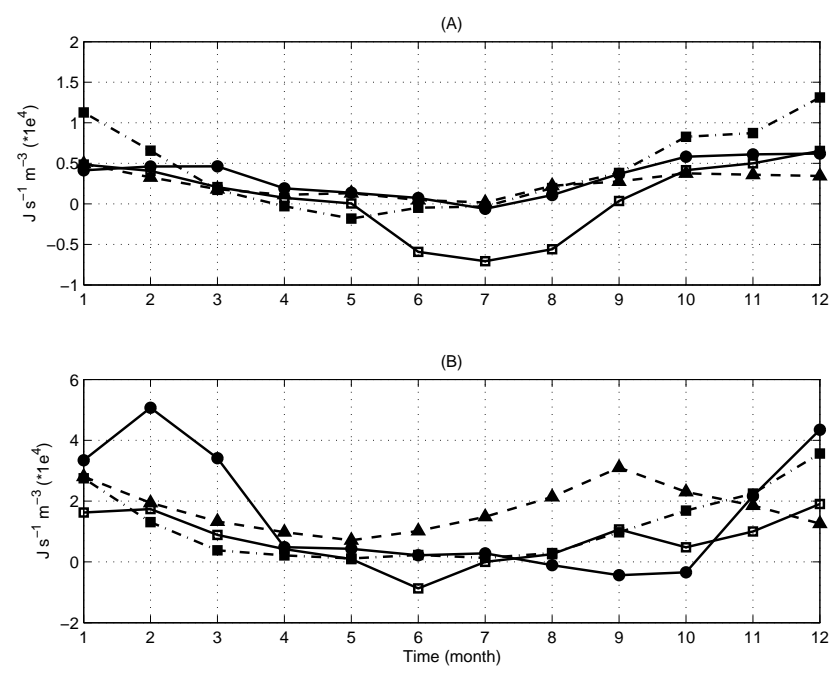

Fig. 14. Monthly time series of BEC for the Sardinia - Tyrrhenian (solid line and circle), Sicily Channel (solid line and empty square), Tunisian (dashed-dotted line and full squares) and Libyan (dashed line and triangles) sub-regions, as reported in Fig. 1, averaged on the period 2008-2010 and vertically integrated from the surface to $5 \mathrm{~m}$ depth (panel A) and from 5 to $80 \mathrm{~m}$ depth (panel B). Unit are $\mathrm{Js}^{-1} \mathrm{~m}^{-3}$. The multiplication factor is $10^{4}$.

The monthly time series of the BEC for the four subregions, vertically integrated from surface to $5 \mathrm{~m}$ depth, (Fig. 14a) show a marked seasonal variability characterized by an energy transfer from EAPE to EKE, mainly occurring from autumn to spring. Only in the Sicily Channel subregion an inversion of the energy conversion, from EKE to EAPE, is well evident and occurs from June to August. A weak signal is observed also into the Sardinia - Tyrrhenian sub-region but with really small values. The Tunisian and Libyan sub-regions show the BEC always positive. This means that the energy conversion is in the direction from EAPE to EKE throughout the year. Highest levels of BEC $\left(>0.5 \mathrm{e}^{-5} \mathrm{~J} \mathrm{~s}^{-1} \mathrm{~m}^{-3}\right)$ in the Tunisian sub-region are found from October to March while from December to February maxima are located in the Libyan sub-region (lower than $\left.0.5 \mathrm{e}^{-5} \mathrm{~J} \mathrm{~s}^{-1} \mathrm{~m}^{-3}\right)$. Furthermore in the Tunisian-Libyan subregion the temporal evolution of BEC is in phase with the corresponding EKE and with the wind forcing (see Fig. 5b and e). The other sub-region shows a more complicated relationship probably due to the fact that the core of AW along its circulation paths is characterized by a seasonal variability, especially with respect to its depth and thickness (Sorgente et al., 2003). For this reason it is interesting to investigate the temporal trend of the BEC integrated below the superficial layers ( 5 to $80 \mathrm{~m}$ depth). The monthly time series of the BEC, integrated below the superficial layer for each sub-region, is shown in Fig. 14b. Their signals are characterized by large positive values from November to March, with higher values than those obtained for the surface layer. 

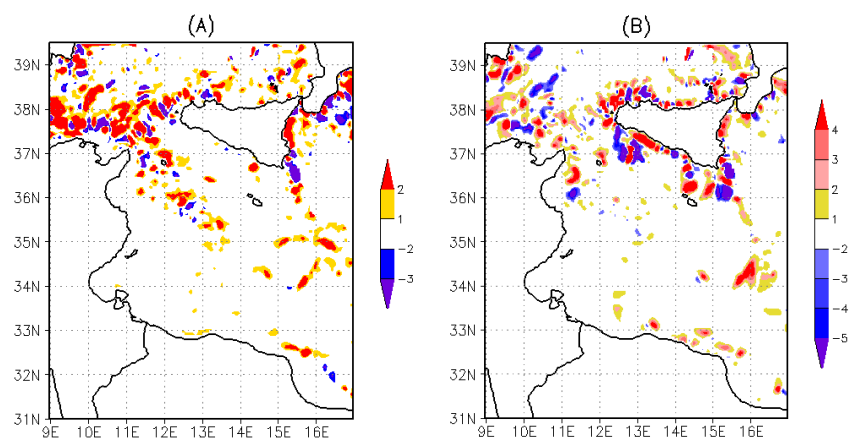

Fig. 15. Monthly mean maps of BEC integrated from 5 to $80 \mathrm{~m}$ depth in February (panel A) and July (panel B), averaged on the period 2008-2010. Positive values indicate energy transfer from Eddy Available Potential Energy to EKE. Units are $\mathrm{Js}^{-1} \mathrm{~m}^{-3}$. The multiplication factor is $10^{4}$.

In the Sardinia - Tyrrhenian sub-region the BEC (Fig. 14b, solid line and circles) is almost two-three times larger than in the other sub-regions. Its temporal behaviour shows a large energy transfer from EAPE to EKE from November to March $\left(>2 \mathrm{e}^{-5} \mathrm{~J} \mathrm{~s}^{-1} \mathrm{~m}^{-3}\right)$, located over the fast flowing currents AC and BTC (Fig. 15a). This would be reasonably due to the density gradient generated between the inflow of modified AW through the Sardinia Channel (see Fig. 7) and resident water masses. From April to June the BEC is slightly positive while the inverse energy transfer mainly occurs in summer reaching its maximum in October. The BEC appears related to the correspondent EKE time series (Fig. 5b) and the inflow of modified AW through the Sardinia Channel (Fig. 7). Then, in this area part of the mesoscale dynamics seems to be due to the energy conversion from EAPE to EKE, typical of baroclinic instability processes connected to the inflow of modified AW.

The Sicily Channel sub-region shows a slightly different trend in terms of energy conversion processes. The BEC signal (see Fig. 14b, solid line and empty square) is characterized by smaller values than those observed in the Sardinia Channel and by a positive seasonal cycle nearly throughout the year. The maximum energy transfer from EAPE to EKE occurs in February while we observe the inverse process in June. The BEC does not appear directly related to the EKE behaviour (see Fig. 5b). This is clearly evident if we consider the summer period when the EKE reaches its minimum in July and October. This weaker or null relation between the BEC and EKE suggests that, in the Sicily Channel sub-region, the BEC is not the only source/loss of energy (Fig. 15b). In this area an important role would be played by the advective flows associated to the AIS, ATC and BATC, as well by the atmospheric forcing and the topographic constrain.
Contributes to the domain averaged BEC in the Tunisian and Libyan sub-regions are always positive. This means that the energy conversion from EAPE to EKE occurs throughout the year at this layer. Highest levels of contribution to the baroclinic instability in the Tunisian sub-region mainly occur from October to February (see Fig. 14b, dashed line and squares), well related to the EKE (see Fig. 5b). Differently the Libyan sub-region is the only sub-region where the energy conversion reaches its maximum value in late summer (see Fig. 14b, dashed line and triangle), well related to the EKE time series (see Fig. 5b). Thus the internal energy redistribution processes reach their maximum in September when the work due to atmospheric forcing is almost at its lowest intensity (see Fig. 5e). This is associated with the inverse baroclinic energy conversion processes, where the EKE field motion restores the vertical and horizontal shears. In fact this region can accumulate EAPE during the winter then released to EKE during summer, when the BEC maxima are found above all in the Sicily Channel, along the southern Sicilian coast, due to the strong density gradient between the AIS and surrounding waters (Fig. 15b).

\section{Conclusions}

The circulation in the CMED has been simulated from January 2008 to December 2010 using a high resolution primitive equations numerical model. The aim was to assess the spatial and temporal mesoscale variability and evaluate its relationships with the atmospheric forcing (winds) and the energy redistribution processes. So the simulated flow field has been decomposed into a mean and eddy (fluctuating) component that have been used to compute, respectively, the MKE (the kinetic energy of the mean flow) and the EKE (the kinetic energy of the fluctuating component); the latter assumed as a good indicator for mesoscale activity. Moreover, the spatial and temporal variability of the BEC has been analysed in order to identify part of mesoscale activity due to baroclinic instabilities.

On the base of known oceanographic characteristics the model domain has been divided into 4 different sub-regions (Fig. 1): Sardinia-Tyrrhenian; Sicilian; Tunisian shelf; Libyan area.

The Sardinia-Tyrrhenian appears as the most energetic sub-region. It is dominated by the seasonal modulation of the AC, seasonal reversal of the BTC, the presence and action of the quasi-permanent SESG and by a significant mesoscale activity in the form of mesoscale eddies $(<100 \mathrm{~km})$ in agreement with Sammari et al. (1999). These eddies are mainly induced by baroclinic instabilities of the AC. Our results show that this process is seasonal, more evident in fall-winter than in summer and related to the wind stress forcing and to the eastward flow at the Sardinian-Tunisian section, This is confirmed by the energy transfer from EAPE to EKE occurring from September to February while a weak inverse energy transfer is clear from April to June. 
The Sicily sub-region appears less energetic than the Sardinia - Tyrrhenian. MKE and EKE have almost comparable values without a clear seasonal cycle. The surface circulation is dominated by the seasonal modulation between ATC (maximum in winter and fall) and AIS (in summer), by intermittent eddy features, meanders and fronts which define the horizontal distribution of the surface waters. The footprints of the ATC in the MKE and the EKE fields indicate the ATC as a coastal boundary current, rather variable, flowing along the eastern Tunisian slope mainly from November to June in agreement with Sorgente et al. (2003) and Béranger et al. (2004). The ATC is often accompanied by the PV, a small and intermittent mesoscale feature, induced by the potential vorticity stretching which can be involved on the recirculation of the AW into the Sicily Channel toward the Tunisian - Sicily section. During the summer months the ATC tends to vanish and it is replaced by a counter-current close to Cape Bon that is accompanied by a complex system of small cyclonic and anti-cyclonic eddies induced by baroclinic instabilities. In the same months the MKE is sustained by the AIS which moves eastward with the typical waveform around permanent mesoscale features such as the Adventure Bank Vortex, the Maltese Channel Crest and the Ionian Shelf break Vortex (Robinson et al., 1999; Lermusiaux, 2001). In winter the AIS appears as a less intense coastal boundary current confined along the southern Sicilian coast, in agreement with satellite observations (Ciappa, 2009).

The Tunisian shelf sub-region appears characterized by strong mesoscale variability with an EKE two-three times larger than in other areas. Here, the contribution of the fluctuating component of the velocity to the total kinetic energy reaches about $90 \%$ on annual basis. Although this is a shallow water area, the wind stress does not seem to be the primary source of energy at monthly scale. On the contrary, high EKE values seem mainly due to the baroclinic instabilities of the seasonal currents flowing eastward over the Tunisian shelf. The analysis of BEC indicates that this sub-region is characterized by a permanent energy conversion from EAPE to EKE. This can be explained taking in mind that in this area sudden current reversals take place. The effect of such reversals, in terms of enhancement of the variability, is increased by a flat and shallow bathymetry and by the unsettled advection of ATC over the wide shelf.

The Libyan sub-region is fairly unknown in terms of dynamics and water masses due to a strong lack of observational data, although recent observations are beginning to fill this gap (Gasparini et al., 2008; Ciappa, 2009). The surface circulation appears complex and characterized by the seasonal modulation of the ALC and by the presence of gyres, eddies and current bifurcations. The EKE, that appears uncupled with Wsw, is about two times higher than the MKE with a weak seasonal signal. The model shows some unfamiliar features like the BATC and ALC (the eastward extension of the ATC). The former appears as a weak and stable current flowing toward the open Ionian Sea and has been re- cently identified by Gerin (2009) and Ciappa (2009). This current is particularly evident from November to April and constitutes the main mechanism for the advection of AW outside the Sicily Channel. The ALC follows along the Libyan coast, south of the Sidra Gyre, from November to April, rather energetic and highly variable. Its existence is supported by Gasparini et al. (2008) and Poulain and Zambianchi (2007). Ciappa (2009) as well, by means of satellite chlorophyll images, observed the ALC, although he stated that this current cannot be considered a branch of the ATC. The presence, strength and horizontal extension of the ALC and BATC are influenced by a complex system of cyclonic and anti-cyclonic mesoscale eddies. The largest is the Sidra Gyre that blocks or reduces the advection of AW along Libya deviating it offshore towards the open Ionian Sea.

In conclusion, the decomposition and analysis of the kinetic energies proved its utility in identifying areas and periods where mesoscale phenomena are more evident and to weigh their relevance to the mean flow. The model results indicate that the mesoscale circulation (described through the EKE) represents an important component of the flow over the entire study area but having important differences between the various sub-regions. The BEC analysis allowed to partially understand the mechanisms driving the presenceabsence of a mesoscale activity, underlying further differences between the four sub-regions. The baroclinic instabilities that can contribute to the EKE signal are mainly located on the boundaries of the large-scale current systems, still retaining a seasonal signal. High values of EKE can be connected to the baroclinic instabilities especially on AC and BTC in winter and on AC and ATC in fall. The model also reveals its ability in reproducing the surface and subsurface circulation features known by literature as well in the identification of some new structures and streams, often verified through satellite data, and contributing to further explain circulation mechanisms in the region. A direct verification would be needed for the Westward Northern Sicilian Current, a westward current identified on model results (not shown) as a stream flowing along the northern Sicilian coast particularly strong in summer. Finally the results of this work will be helpful to improve the sampling design (space and time frequency of casts) in oceanographic cruises addressed to the study of the mesoscale dynamics in the Central Mediterranean region. 
Acknowledgements. This work is part of the project European COastal sea OPerational observing and forecasting system integrated project funded by the European Commission Sixth Framework Programme, under the priority Sustainable Development, Global Change and Ecosystems. Contract No. 36355. This work is part also of the project SOS-BONIFACIO (contract DEC/DPN 2291 of 19/12/2008) funded by the Directorate General for Nature Protection of the Italian Ministry for Environment, Land and Sea. Finally we must also thank our wallets without which we would not be able to carry out this research.

Edited by: S. Cailleau

\section{References}

Artale, V., Astraldi, M., Buffoni, G., and Gasparini, G. P.: Seasonal variability of gyre-scale circulation in the Northern Tyrrhenian Sea, J. Geophys. Res. Ocean, 99(C7), 14127-14137, 1994.

Astraldi, M., Gasparini, G. P., Sparnocchia, S., Moretti, S., and Sansone, E.: The characteristics of the Mediterranean water masses and the water transport in the Sicily Channel at longtime scale, edited by: Briand, F., Dynamics of the Straits and Channels, 2, CIESM Science Series, Monaco, 95-118, 1996.

Astraldi, M., Balopoulos, S., Candela, J., Font, J., Gacic, M., Gasparini, G. P., Manca, B., Theocharis, A., and Tintoré, J.: The role of straits and channels in understanding the characteristics of Mediterranean circulation, Prog. Oceanogr., 44, 65-108, 1999.

Astraldi, M., Gasparini, G. P., Vetrano, A., and Vignudelli, S.: Hydrographic characteristics and interannual variability of water masses in the central Mediterranean: a sensitivity test for longterm changes in the Mediterranean Sea, Deep-Sea Res. Pt. I, 49, 661-680, 2002.

Auclair, F., Casitas, S., and Marsaleix, P.: Application of an Inverse Method to Coastal Modeling, J. Atmos. Ocean Technol., 17, 1368-1391, 2000.

Béranger, K., Astraldi, M., Crépon, M., Mortier, L., Gasparini, G. P., and Gervaso, L.: The dynamics of the Sicily Strait: a comprehensive study from observations and models, Deep-Sea Res. Pt. II., 411-440, 2004.

Béranger, K., Mortier, L., and Crépon, M.: Seasonal variability of water transport through the Straits of Gibraltar, Sicily and Corsica, derived from a high-resolution model of the Mediterranean circulation, Prog. Oceanogr., 66, 341-364, 2005.

Bignami, F., Marullo, S., Santoleri, L., and Schiano, M. E.: Longwave radiation budget in the Mediterranean Sea, J. Geophys. Res., 100, 2501-2514, 1995.

Blumberg, A. F. and Mellor, G. L.: A description of a threedimensional coastal ocean circulation model, edited by: Heaps, N. S., Three-dimensional coastal ocean models, American Geophysical Union, Washington D.C., 208, 1-16, 1987.

Borzelli, G. and Ligi, R.: Autocorrelation Scales of the SST Distribution and Water Masses Stratification in the Channel of Sicily, J. Atmos. Ocean. Technol., 16, 776-782, 1998.

Brasseur, P., Beckers, J. M., Brankart, J. M., and Schoenauen, R.: Seasonal temperature and salinity fields in the Mediterranean Sea: Climatological analyses of an historical data set, Deep-Sea Res., 43, 2, 159-192, 1996.
Castellari, S., Pinardi, N., and Leaman, K.: A model study of air-sea interaction in the Mediterranean Sea, J. Mar. Syst., 18, 89-114, 1998.

Ciappa, A. C.: Surface circulation pattern in the Sicily Channel and Ionian Sea as revealed by MODIS chlorophyll images from 2003 to 2007, Cont. Shelf Res., 29, 17, 2099-2109, 2009.

Drago, A. F., Sorgente, R., and Ribotti, A.: A high resolution hydrodynamic 3-D model simulation of the malta shelf area, Ann. Geophys., 21, 323-344, doi:10.5194/angeo-21-323-2003, 2003.

Fernàndez, V., Dietrich, D. E., Haney, R. L., and Tintorè, R. L.: Mesoscale, seasonal and interannual variability in the Mediterranean Sea using a numerical ocean model, Prog. Oceanogr., 66, 321-340, 2005.

Gaberšek, S., Sorgente, R., Natale, S., Ribotti, A., Olita, A., Astraldi, M., and Borghini, M.: The Sicily Channel Regional Model forecasting system: initial boundary conditions sensitivity and case study evaluation, Ocean Sci., 3, 31-41, doi:10.5194/os-331-2007, 2007.

Gasparini, G. P., Smeed, D. A., Alderson, S., Sparnocchia, S., Vetrano, A., and Mazzola, S.: Tidal and subtidal currents in the Strait of Sicily, J. Geophys. Res., 109, C02011, doi:10.1029/2003JC002011, 2004.

Gasparini, G. P., Ortona, A., Budillon, G., Astraldi, M., and Sansone, E.: The effect of the Eastern Mediterranean transient on the hydrographic characteristics in the Straits of Sicily and in the Tyrrhenian Sea, Deep-Sea Res. Pt. I, 52, 915-935, 2005.

Gasparini, G. P., Bonanno, A., Zgozi, S., Basilone, G., Borghini, M., Buscaino, G., Cuttitta, A., Essarbout, N., Mazzola, S., Patti, B., Ramadan, A. B., Schroeder, K., Bahri, T., and Massa, F.: Evidence of a dense water vein along the Libyan continental margin, Ann. Geophys., 26, 1-6, doi:10.5194/angeo-26-1-2008, 2008.

Gerin, R., Poulain, P.-M., Taupier-Letage, I., Millot, C., Ben Ismail, S., and Sammari, C.: Surface circulation in the Eastern Mediterranean using drifters (2005-2007), Ocean Sci., 5, 559574, doi:10.5194/os-5-559-2009, 2009.

Hamad, N., Millot, C., and Taupier-Letage, I.: A new hypothesis about the surface circulation in the eastern basin of the Mediterranean Sea, Prog. Oceanogr., 66(2-4), 287-298, 2005.

Hellerman, S. and Rosenstein, M.: Normal monthly wind stress over the world ocean with error estimates, J. Phys. Oceanogr., 13, 1093-1104, 1983.

Herbaut, C., Codron, F. and Crepon, M.: Separation of a Coastal Current at a Strait Level: Case of the Strait of Sicily, J. Phys. Oceanogr., 28, 1346-1362, 1998.

Kondo, J.: Air Sea bulk transfer coefficients in adiabatic conditions, Bound-Layer Meteorol., 9(1), 91-112, doi:10.1007/BF00232256, 1975.

Korres, G., Pinardi, N., and Lascaratos, A. The ocean response to low-frequency interannual atmospheric variability in the Mediterranean Sea. Part 1: Sensitivity experiments and energy analyses, J. Climate, 13(4), 705-731, 2000.

Legates, D. R. and Willmott, J.: Mean seasonal and spatial variability in a gauge corrected global precipitation, Int. J. Climatol., 10, 121-127, 1990.

Lermusiaux, P. F. J.: Estimation and study of mesoscale variability in the Strait of Sicily, Dynam. Atmos. Oceans, 29, 255-303, 1999.

Lermusiaux, P. F. J. and Robinson, A. R.: Features of dominant mesoscale variability, circulation patterns and dynamics in the 
Strait of Sicily, Deep-Sea Res. Pt. I, 48, 1953-1997, 2001.

Lorenz, E. N.: Available potential energy and the maintenance of the general circulation, Tellus, 7, 157-167, 1955.

Manzella, G. M. R., Gasparini, G. P., and Astraldi, M.: Water Exchange between the eastern and western Mediterranean through the Strait of Sicily, Deep-Sea Res. Pt. I, 35(6), 1021-1035, 1988.

Manzella, G. M. R. and La Violette, P.: The seasonal variation of water mass content in the western Mediterranean and its relationship with the inflow through the Strait of Gibraltar and Sicily, J. Geophys. Res., 95(C2), 1623-1626, 1990.

Manzella, G. M. R., Hopkins, T. S., Minnet, P. J., and Nancini, E.: Atlantic water in the Strait of Sicily, J. Geophys. Res., 95(C7), 1569-1575, 1990.

Mellor, G. L. and Yamada, T.: Development of a turbulent closure model for geophysical fluid problems, Rev. Geophys. Space Phys., 20, 851-875, 1982.

Mellor, G. L.: An equation of state for numerical models of oceans and estuaries, J. Atmos. Ocean. Tech., 8, 609-611, 1991.

Mellor, G. L., Ezer, T., and Oey, L. Y.: The pressure gradient conundrum of sigma coordinate ocean models, J. Atmos. Ocean. Tech., 11(4), 1126-1134, 1994.

Millot, C.: Circulation in the Western Mediterranean Sea, J. Mar. Syst., 20(1-4), 423-442, 1999.

Molcard, A., Gervasio, L., Griffa, A., Gasparini, G. P., Mortier, L., and Ozgokmen, T. M.: Numerical investigation of the Sicily Channel dynamics: density currents and water mass advection, J. Mar. Syst., 36, 219-238, 2002.

Oddo, P. and Pinardi, N.: Lateral open boundary conditions for nested limited area models: A scale selective approach, Ocean Model., 20, 134-156, 2008.

Oddo, P., Pinardi, N., and Zavatarelli, M.: A numerical study of the interannual variability of the Adriatic Sea (2000-2002), Sci. Total Environ, 353, 39-56, 2005.

Oddo, P., Adani, M., Pinardi, N., Fratianni, C., Tonani, M., and Pettenuzzo, D.: A nested Atlantic-Mediterranean Sea general circulation model for operational forecasting, Ocean Sci., 5, 461-473, doi:10.5194/os-5-461-2009, 2009.

Olita, A., Sorgente, R., Natale, S., Gaberšek, S., Ribotti, A., Bonanno, A., and Patti, B.: Effects of the 2003 European heatwave on the Central Mediterranean Sea: surface fluxes and the dynamical response, Ocean Sci., 3, 273-289, doi:10.5194/os-3273-2007, 2007.

Onken, R. and Sellschopp, J.: Water masses and circulation between the eastern Algerian basin and the Strait of Sicily in October 1996, Oceanol. Acta, 24, 151-166, 2001.

Onken, R., Robinson, A. R., Lermusiaux, P. F. J., Haley, P. J., and Aanderson, A. L.: Data-driven simulations of synoptic circulation and transports in the Tunisian-Sardinia-Sicily region, J. Geophys. Res. 108(C9), 8123-8136, 2003.

Orlansky, I. and Katzfey, J.: The life Cycle of a cyclone Wave in the southern Hemisphere, Part I: Eddy Energy Budget, J. Atmos. Sci., 48(17), 1972-1998, 1991.

Pedlosky, J.: Geophysical Fluid Dynamics, 2nd Edition, Springer, 710 pp., Berlin, 1987.

Pedlosky J., Ocean Circulation Theory, Springer-Verlag, New York, 464 pp., 1996.

Pinardi, N. and Masetti, E.: Variability of the large scale general circulation of the Mediterranean Sea from observations and modeling: a review, Paleogeography, Palaeoclimatology, Palaeoecol- ogy, 158, 153-173, 2000.

Pierini, S. and Rubino, A.: Modeling the Ocean Circulation in the Area of the Sicily Strait: the Remotely Forced Dynamics, J. Phys. Oceanogr., 31, 1297-1412, 2001.

Pinardi, N. and Navarra, A.: Baroclinic wind adjustment processes in the Mediterranean Sea, Deep-Sea Res. Pt. II, 40, 1299-1326, 1993.

Pinardi, N., Korres, G., Lascaratos, A., Roussenov, V., and Stanev, E.: Numerical simulation of the interannual variability of the Mediterranean Sea upper ocean circulation, Geophys. Res. Lett., 24(4), 425-428, 1997.

Pinardi, N., Allen, I., Demirov, E., De Mey, P., Korres, G., Lascaratos, A., Le Traon, P.-Y., Maillard, C., Manzella, G., and Tziavos, C.: The Mediterranean ocean forecasting system: first phase of implementation (1998-2001), Ann. Geophys., 21, 3-20, doi:10.5194/angeo-21-3-2003, 2003.

Poulain, P. M. and Zambianchi, E.: Surface circulation in the central Mediterranean Sea as deduced from Lagrangian drifters in the 1990s, Cont. Shelf Res., 27, 981-1001, 2007.

Reed, R. K.: On estimating insolation over the ocean, J. Phys. Oceanography, 17, 482-485, 1977

Robinson, A. R., Sellschopp, J., Warn-Varnas, A., Leslie, W. G., Lozano, C. J., Haley Jr., P. J., Anderson, L. A., and Lermusiaux, P. F. J.: The Atlantic Ionian Stream, J. Mar. Syst., 20, 129-156, 1999.

Robinson, A. R., Wayne, G., Thecharis, A., and Lascaratos, A.: Mediterranean Sea circulation, in: Encyclopedia of Ocean Sciences, edited by: Steele, J., Turekian, K., and Thorpe, S., Academic Press, 2001.

Sammari, C., Millot, C., Taupier-Letage, I., Stefani, A., and Brahim, M.: Hydrological characteristics in the TunisianSardinia-Sicily area during spring 1995, Deep-Sea Res. Pt. I 46, 1671-1703, 1999.

Schlitzer, R., Roether, W., Oster, H., Junghans, H., Hausmann, M., Johannsen, H., and Michelato, A.: Chlorofluoromethane and Oxygen in the Eastern Mediterranean, Deep-Sea Res. Pt. I, 38(12), 1531-1551, 1991.

Smagorinsky, J.: Some historical remarks on the use of nonlinear viscosities, in: Large eddy simulations of complex engineering and geophysical flows, edited by: Galperin, B., and Orszag, S., Cambrige Univ. Press, 1-34, 1993.

Sorgente, R., Drago, A. F., and Ribotti, A.: Seasonal variability in the Central Mediterranean Sea circulation, Ann. Geophys., 21, 299-322, doi:10.5194/angeo-21-299-2003, 2003.

Tonani, M., Pinardi, N., Dobricic, S., Pujol, I., and Fratianni, C.: A high-resolution free-surface model of the Mediterranean Sea, Ocean Sci., 4, 1-14, doi:10.5194/os-4-1-2008, 2008.

Vetrano, A., Gasparini, G. P., Molcard, R., and Astraldi, M.: Water flux estimates in the central Mediterranean Sea from an inverse box model, J. Geophys. Res., 109, 1-24, C01019, 2004.

Zavatarelli, M. and Mellor, G. L.: A numerical study of the Mediterranean Sea circulation, J. Phys. Oceanogr., 1384-1414., 1995.

Zavatarelli, M. and Pinardi, N.: The Adriatic Sea modelling system: a nested approach, Ann. Geophys., 21, 345-364, doi:10.5194/angeo-21-345-2003, 2003.

Zhai, X. and Greatbatch, R. J.: Wind work in a model of the northwest Atlantic Ocean, Geophys. Res. Lett., 34, L04606, doi:10.1029/2006GL028907, 2007. 